\title{
Demographics, clinical features and treatment of pediatric celiac disease
}

\author{
Dimitrios Tapsas
}

\author{
Faculty of Medicine and Health Sciences \\ Division of Pediatrics \\ Department of Clinical and Experimental Medicine, IKE \\ Linköping University \\ SE-581 83 Linköping, Sweden
}

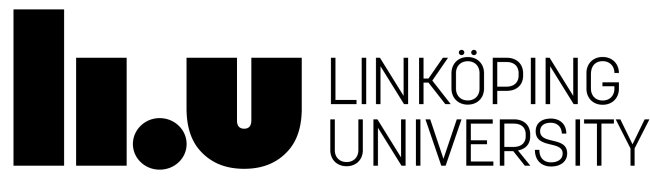


Funding was received from the Medical Research Council of Southeast Sweden, the County Council of Östergötland and the Swedish Research Council for the completion of the present thesis.

(C) Dimitrios Tapsas, 2015

(C) Cover design: Spyros Taramigkos, 2015

Published articles have been reprinted with the permission of the respective copyright holder: Elsevier Inc. (paper III C 2014)

Taylor \& Francis (paper IV (C) 2014)

ISSN 0345-0082

ISBN: 978-91-7685-977-3

Printed in Sweden by LiU-Tryck, Linköping 2015 
with best regards from the author 
To my beloved family and friends

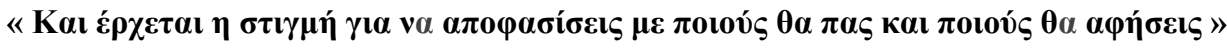




\section{ABSTRACT}

Celiac disease $(\mathrm{CD})$ is a chronic small intestinal immune-mediated enteropathy triggered by ingestion of gluten-containing food in genetically predisposed subjects. The enteropathy is presented with a wide variety of clinical manifestations, which can occur even outside the gastrointestinal tract. In the majority of cases, the diagnosis of CD is based on a small intestinal biopsy showing mucosal alterations, i.e. intraepithelial lymphocytosis, crypt hyperplasia, and villous atrophy. The treatment, gluten-free diet (GFD), has recently been revised with the addition of gluten-free oats. Oats give a more diversified nutrition and increase the fibre content. The use of oats in $\mathrm{CD}$ is though still debated in some reports. A strict life-long adherence to the GFD can be problematic, especially for pediatric CD patients. Sweden reported of one of the highest observed CD prevalences worldwide, i.e. 3\%, among 12-year-olds born during what has been described as "the Swedish celiac epidemic", 1984-1996.

The aims of this thesis were to elucidate how pediatric CD has changed during a 41-year period in Sweden, i.e. 1973-2013, in terms of clinical presentation, disease severity, incidence, and demographics. We also wanted to adress the compliance to the GFD, the use of oats in the GFD and the safety of oats inclusion in the diet by measuring urinary nitric oxide (NO) metabolites.

Filed information provided data about 2856 pediatric patients investigated for suspected CD between 1973 and 2013; of which 1030 patients were diagnosed with CD. After the data analyses the mean age of $\mathrm{CD}$ patients was shown to increase after the celiac epidemic period. Currently, CD shows a less severe picture in terms of symptoms and intestinal pathology. Younger children suffer primarily from gastrointestinal symptoms and growth failure, whereas extra-intestinal manifestations are more often displayed among adolescents. 
We also reported an unusually high pediatric CD incidence rate and cumulative incidence, likely the highest reported worldwide. We hypothesised that the introduction of new antibody tests would affect the diagnostic activity and accuracy in performing small intestinal biopsies for CD investigation. However, the outcome of diagnostic activity and accuracy could not clearly be attributed to the use of antibody tests due to changes occurring in parallel during the 41-year study period, e.g. a different pattern of symptoms at presentation and improved knowledge of the disease among parents and health professionals.

In a questionnaire-based study our patient group reported a high compliance to the GFD. Long duration of the GFD may, however, influence compliance negatively. Oats have been included to the GFD of our study population in most of the cases without reporting major complications related to their well-being.

The urinary measurements of NO metabolites revealed two patient groups, one with high and one with low levels. The two populations did not differ regarding sex, age, compliance to the GFD or oats consumption. Factors such as nitrate-rich foods, asthma or urinary tract infections did not affect the results. The high levels could possibly be attributed to poor adherence to the GFD, sensitivity to oats, or some unknown factor(s). The elevated levels of NO metabolites might indicate mucosal inflammation and pinpoint the need of careful follow-up of children on oats-containing GFD as not all of them might tolerate oats. 


\section{SVENSK SAMMANFATTNING}

Celiaki (CD), är en kronisk inflammation i tunntarmens slemhinna utlöst efter intag av gluteninnehållande föda hos individer med genetisk förutsättning. Symptomen på celiaki kommer framförallt från magtarmkanalen men även andra organ kan drabbas. I de flesta fall är diagnosen CD baserad på en tunntarmbiopsi som karakteriseras av förändringar i slemhinnan, och därmed dåligt näringsupptag. Behandlingen, den glutenfria dieten (GFD), har nyligen reviderats med tillägg av vetefri havre. Havre ger en mer allsidig kost och ökar samtidigt fiberinnehållet. Möjligheten att använda havre i CD har debatterats länge men anses numera riskfritt för majoriteten av patienter. En strikt livslång följsamhet till GFD kan dock vara problematisk för barn med CD. I Sverige har det rapporterats om en av de högsta observerade CD förekomsterna över hela världen, 3\%, bland de 12-åringar som föddes under vad som har beskrivits som "den svenska celiaki-epidemin", 1984-1996.

Syftet med denna avhandling var att belysa hur celiaki i barnåren har ändrats under en 41års period i vår region/Östergötland gällande; klinisk presentation: sjukdomens svårighetsgrad; antal nya fall/år; och demografiska uppgifter. Vi ville också studera följsamheten till GFD, användning av havre i GFD och säkerheten att använda havre i kosten genom att mäta kväveoxid- (NO-) produkter i urinen.

I en lokal databas har vi samlat information om 1030 barn som fått diagnosen CD mellan 1973 och 2013. Analys av dessa data visade att medelåldern hos de som insjuknar i CD har ökat efter celiakiepidemin, samt att sjukdomen idag visar en mindre allvarlig bild vad det gäller symtom och grad av slemhinneförändringar. Yngre barn lider främst av magtarmsymtom och dålig tillväxt, medan tonåringar kan ha symptom från andra organ. 
Vi fann att antalet nya fall/år var mycket hög, sannolikt det högsta rapporterade i hela världen. Förändringarna i diagnostisk verksamhet och noggrannhet kan inte tydligt tillskrivas användningen av nya antikroppstest, möjligen på grund av andra samtidiga förändringar, t.ex. variationer i symtom vid sjukdomsdebut och ökad kunskap om sjukdomen bland föräldrar och vårdpersonal.

I en enkätbaserad studie rapporterade vår patientgrupp en hög följsamhet till GFD. Den långa användningen av GFD kan dock påverka följsamheten negativt. Havre ingick i GFD hos de flesta patienter och de rapporterade inga stora komplikationer som påverkade deras välbefinnande.

Tidigare studier har visat att barn med obehandlad CD har höga halter av kväveoxid-(NO-) metaboliter i urinen och detta kan tolkas som tecken till pågående inflammation i tarmen. Urin-mätningar av NO-produkter bland barn som inkluderar havre i sin GFD avslöjade två patientgrupper: en med höga och en med låga nivåer. De två populationerna skiljde sig inte avseende kön, ålder, följsamhet till GFD och havre konsumtion. Faktorer som nitratrik föda, astma eller urinvägsinfektion påverkade inte resultaten. De höga nivåerna kan möjligen bero på dålig följsamhet till GFD, känslighet mot havre eller någon okänd faktor. De förhöjda nivåerna av NO-metaboliter skulle kunna tyda på att alla inte tolererar havre. Dessa resultat pekar på behovet att noggrant följa upp barn som lagt till havre i sin GFD. 


\section{Contents}

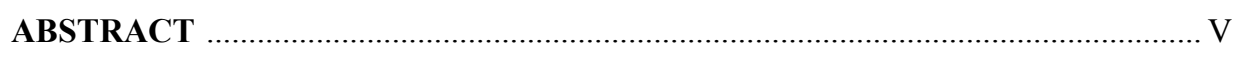

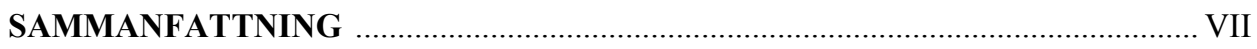

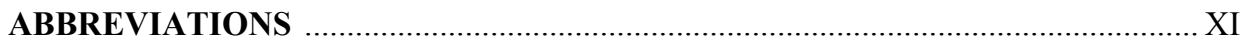

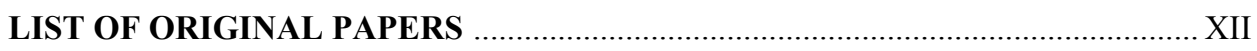

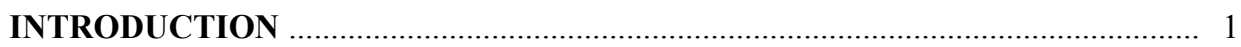

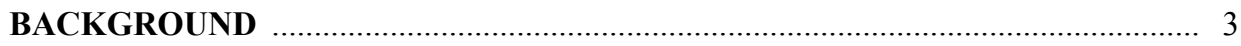

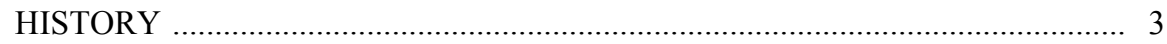

EPIDEMIOLOGY ………………………………………………………... 3

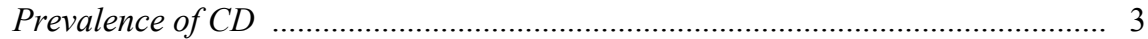

Incidence and the Swedish epidemic of $C D$..................................................... 5

CD, BREASTFEEDING AND GLUTEN INTRODUCTION ................................ 6

DIAGNOSIS .............................................................................................. 6

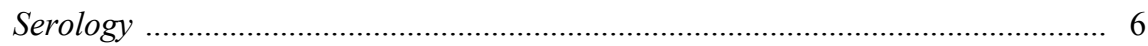

Diagnostic criteria ……………………………………………………... 8

Small intestinal biopsy ............................................................................. 9

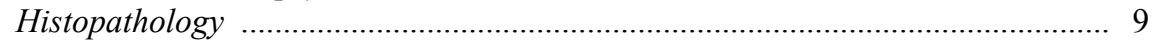

CLINICAL FEATURES AND DEMOGRAPHICS …………………………..... 12

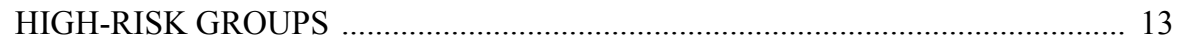

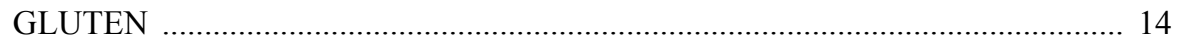

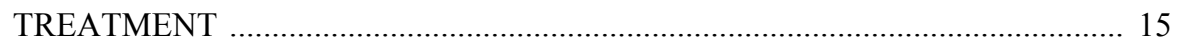

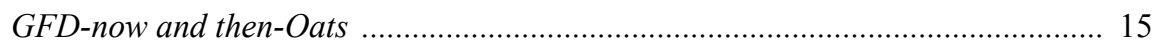

GFD compliance …………………………………………............................ 18

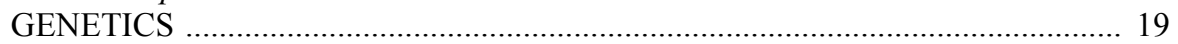

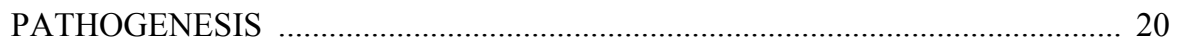

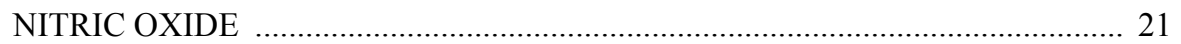

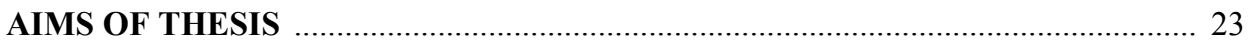

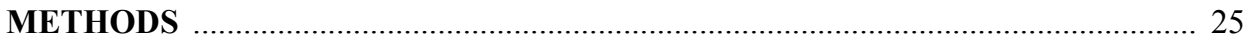

POPULATION AND CATCHMENT AREA (paper I, II, III, IV) .......................... 25

LOCAL DATA COLLECTION (paper I, II) ………………………………...... 25

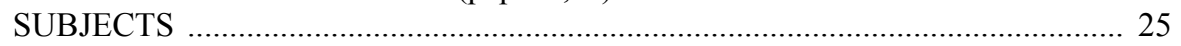

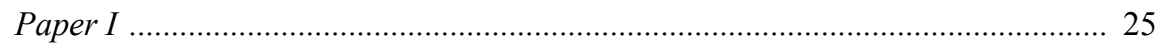

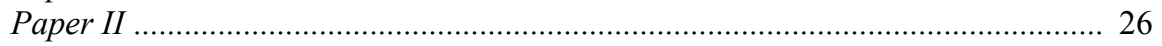

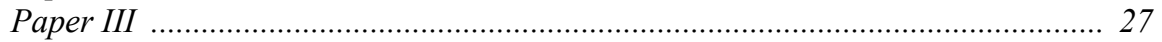

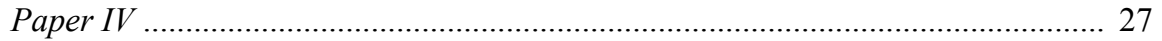

ASSESSMENT OF CLINICAL SYMPTOMS (paper I) ……………………….... 28 


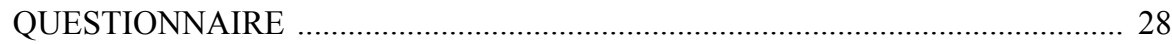

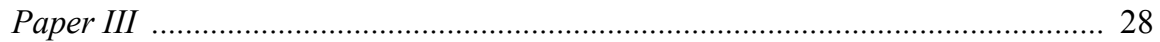

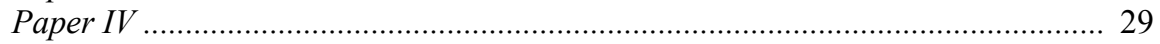

NITRIC OXIDE MEASUREMENTS (paper IV) ................................................ 29

HISTOPATHOLOGICAL EVALUATIONS ................................................. 30

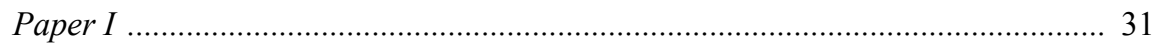

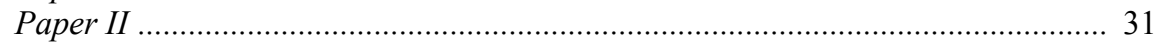

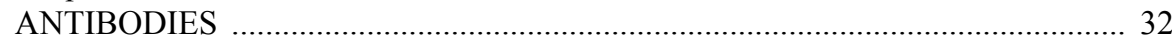

DIAGNOSTIC ACTIVITY \& ACCURACY (paper IV) ....................................... 32

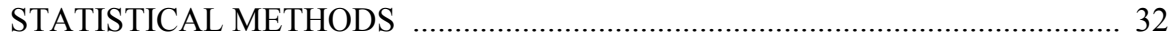

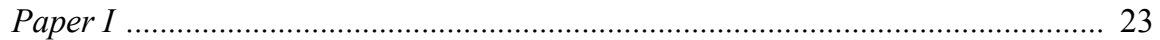

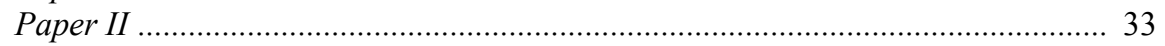

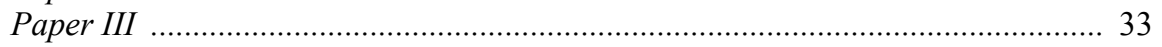

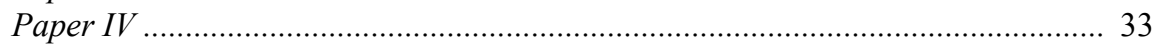

ETHICAL CONSIDERATIONS .................................................................. 34

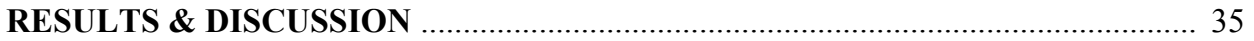

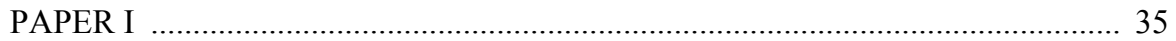

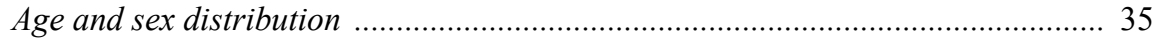

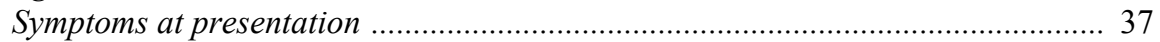

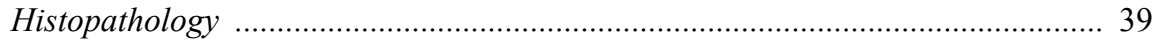

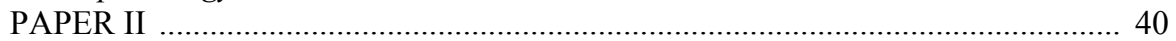

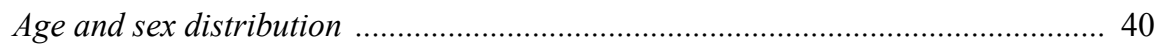

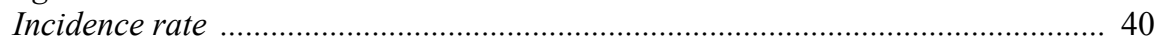

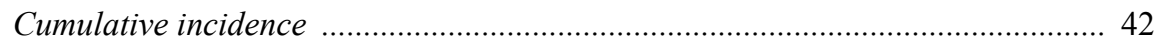

Diagnostic activity ................................................................................. 43

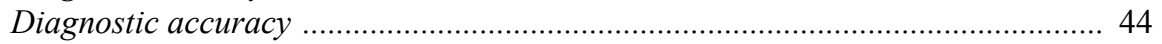

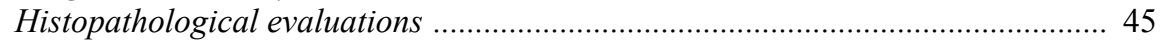

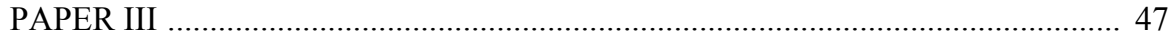

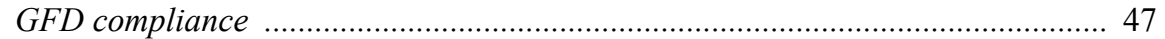

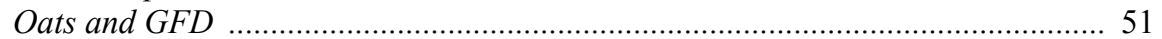

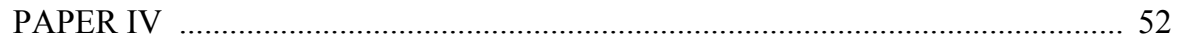

Nitric oxide measurements ........................................................................... 52

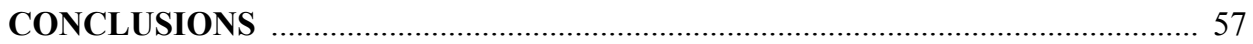

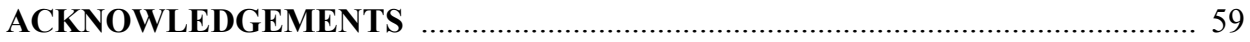

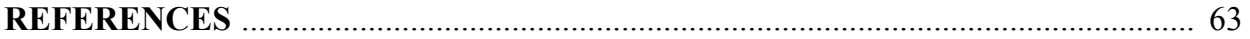




\section{LIST OF ORIGINAL PAPERS}

The present thesis is based on the following papers, which will be referred to in the text by their Roman numerals:

I Dimitrios Tapsas, Elisabet Hollén, Lars Stenhammar, Karin Fälth-Magnusson. The clinical presentation of celiac disease in 1030 Swedish children: changing features over the past 41 years.

Accepted, Digestive and Liver Disease, 28 September 2015

II Dimitrios Tapsas, Elisabet Hollén, Lars Stenhammar, Karin Fälth-Magnusson. Unusually high incidence of paediatric coeliac disease in Sweden during the period 1973-2013.

Submitted

III Dimitrios Tapsas, Karin Fälth-Magnusson, Lotta Högberg, Jan-Åke Hammersjö, Elisabet Hollén.

Swedish children with celiac disease comply well with a gluten-free diet, and most include oats without reporting any adverse effects: a long-term follow-up study.

Nutrition Research, 2014; 34: 436-441

IV Dimitrios Tapsas, Karin Fälth-Magnusson, Lotta Högberg, Tony Forslund, Tommy Sundqvist, Elisabet Hollén.

Urinary nitric oxide metabolites in children with coeliac disease after long-term consumption of oats-containing gluten-free diet.

Scandinavian Journal of Gastroenterology, 2014; 49: 1311-1317 


\section{ABBREVIATIONS}

AGA-anti-gliadin antibodies

CD-celiac disease

CI-confidence interval

DGP- deamidated gliadin peptide

ELISA-enzyme-linked immunosorbent assay

EMA-anti-endomysium antibodies

ESPGHAN-European Society for Paediatric Gastroenterology, Hepatology and Nutrition

FTT-failure to thrive

GFD-gluten-free diet

GWAS-genome-wide association study

HLA-human leucocyte antigen

IELs-intraepithelial lymphocytes

LSD post hoc test-least significant difference post hoc test

NO-nitric oxide

NOS-nitric oxide synthase

cNOS-constitutive nitric oxide synthase

eNOS-endothelial nitric oxide synthase

nNOS-neuronal nitric oxide synthase

iNOS-inducible nitric oxide synthase

PBS-phosphate buffered saline

ppm-parts per million

SBB-small bowel biopsy

t-TGA-anti-tissue transglutaminase antibodies

TGI-transient gluten intolerance 


\section{INTRODUCTION}

Celiac disease $(\mathrm{CD})$ can be defined as a chronic small intestinal immune-mediated enteropathy that develops in genetically susceptible individuals, after ingestion of dietary gluten (Ludvigsson 2013). CD is considered to be one of the most common chronic pediatric disorders in the Western world with a total prevalence varying between $0.5 \%$ and $1 \%$ (Dubé 2005, Mustalahti 2010). During what has been described as "the Swedish celiac epidemic", 1984-1996, reports revealed one of the highest observed prevalences of $\mathrm{CD}$ worldwide, i.e. $3 \%$, among 12-year-olds born during the epidemic (Myléus 2009). Classical CD, is usually presented with signs and symptoms of malabsorption, i.e. diarrhoea, abdominal distention, weight loss, and growth failure. On the contrary, individuals suffering from the non-classical form of CD, develop other types of symptoms, e.g. abdominal pain and constipation, which are not related to the malabsorption syndrome (Fasano 2005 a, Fasano 2005 b, Ludvigsson 2013 b). In recent years, many asymptomatic cases of $\mathrm{CD}$ or patients with vague symptoms are dectected because of the increased awareness of the disease and the widespread use of sensitive serological tests (Mäki 1988, Reilly 2002, White 2002, Ludvigsson 2004). The intestinal mucosa heals after the introduction of the gluten-free diet (GFD), i.e. abstention from wheat, rye and barley. In recent years oats have been added to the GFD and this would increase the palatability, fibre content, and nutri- tional value of the diet (Peräaho 2004, Resane 2015). Adherence to the GFD, the only known treatment for CD, should be lifelong (Green 2007).

The present thesis provides information regarding demographical features, incidence rate and cumulative incidence, of pediatric CD in Sweden during a 41-year period. Data concerning changes of the clinical pattern of $\mathrm{CD}$ at the same period and disease severity will also be discussed. The compliance to the GFD among Swedish children and the inclusion of oats in the 
diet is also assessed along with the safety of a long-term consumption of oats in the GFD by measuring urinary nitric oxide (NO) metabolites, used as a marker of mucosal inflammation. 


\section{BACKGROUND}

\section{HISTORY}

The first description of CD dating back to first century A.D is attributed to the Greek physician Areteus (Walker-Smith 1988). The word celiac derives from the Greek word " коџ $\lambda$ ıокókn" meaning "bad belly". Centuries later, Dr. Samuel Gee suggested that a dietetic factor could be causing the condition (Gee 1888, Losowsky 2008). However, it was not until the 1950s that the link between CD and gluten ingestion was established. The Dutch pediatrician Karel Dicke observed that during World War II and due to shortage of cereals, children with CD improved clinically, and relapsed again when cereal supplies were restored (Dicke 1950, Losowky 2008).

\section{EPIDEMIOLOGY}

\section{Prevalence of CD}

$\mathrm{CD}$ is one of the most common chronic pediatric disorders in the Western world with a screening-detected prevalence among unselected populations of approximately $1 \%$. There are wide variations in the disease prevalence reported worldwide (Figure 1). 


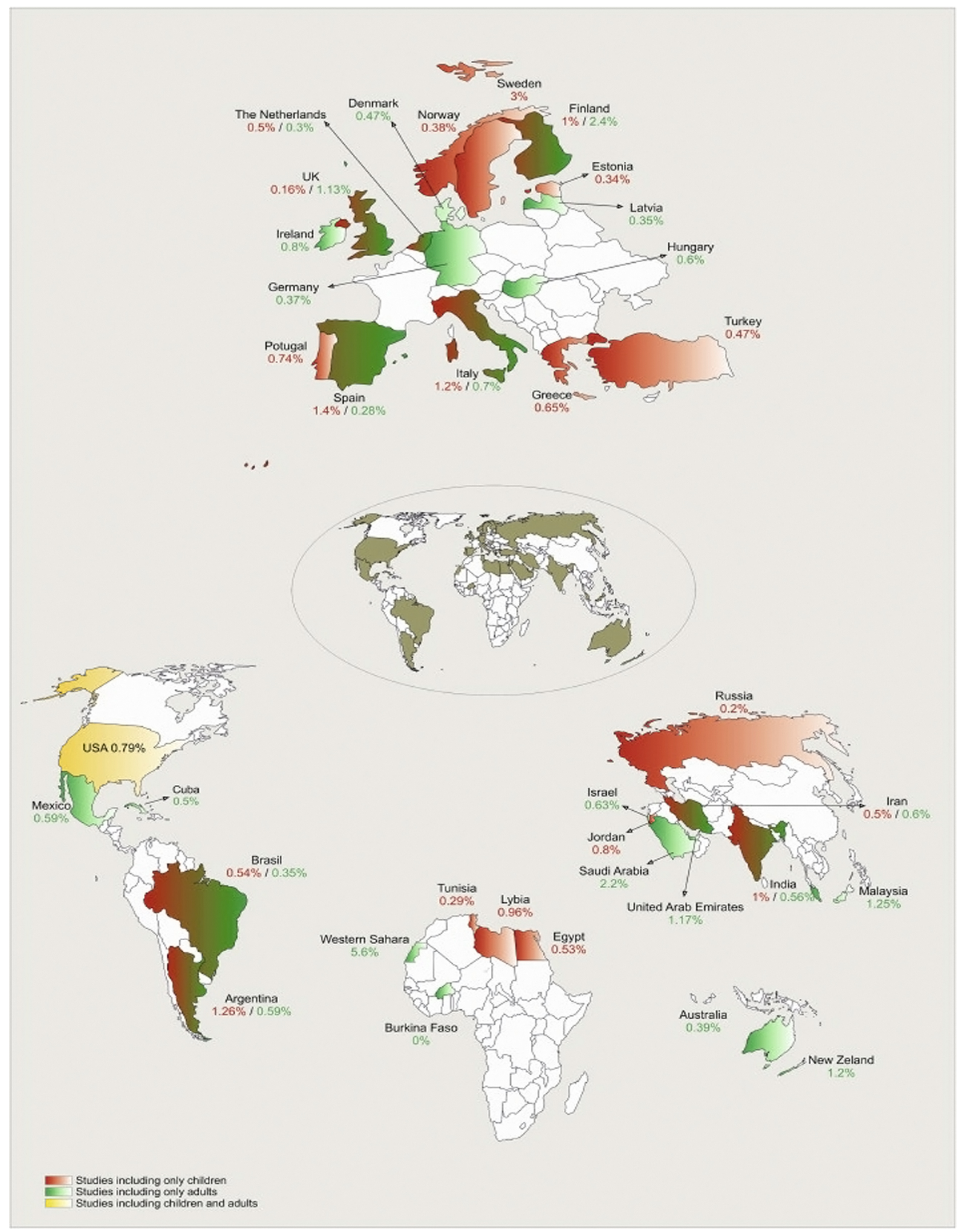

Figure 1. Worldwide prevalence of celiac disease. Countries with published prevalence data are dashed in the central world map. Data were extracted from published studies including data from children (in red color), adults (in green color) or both (in yellow color). (DielliCrimi R, Cénit MC, Núñez C. The genetics of celiac disease: A comprehensive review of clinical implications. J Autoimmun. 2015 Jul 17. pii: S0896-8411(15)30004-4.) 
In Sweden, United Kingdom, and Germany the prevalence exceeded in some studies even 1.5\% (Dubé 2005, Mustalahti 2010). However, many children, especially the asymptomatic ones, may remain undiagnosed (Ravikumara 2007). A Swedish screening study revealed that only $1 / 3$ of children with $\mathrm{CD}$ had been clinically detected and diagnosed before serological testing (Myléus 2009). Myléus et al. reported one of the highest observed prevalences of CD worldwide, i.e. 3\%, among 12-year-olds born during what has been described as "the Swedish celiac epidemic", 1984-1996 (Myléus 2009).

The prevalence values among populations at risk for $\mathrm{CD}$, e.g. patients with type-1 diabetes, Down's syndrome, selective IgA deficiency and first-degree relative with $\mathrm{CD}$, are higher than in general population (Murray 2005, Fasano 2008).

\section{Incidence and the Swedish epidemic of CD}

A CD cumulative incidence of 4.4 per 1000 children born in 1993, i.e. during the celiac epidemic (Ivarsson 2000), reported from Sweden, was one of the highest. This has been partly attributed to a change in Swedish feeding recommendations in 1982 causing delayed (from 4 to 6 months of age) and at the same time a more intense gluten introduction. This occurred as an attempt to postpone the development of $\mathrm{CD}$, in accordance with the Europeran Society for Paediatric Gastroenterology, Hepatology and Nutrition (ESPGHAN) recommendations (ESPGAN committee on nutrition 1982). In 1996 the Swedish Pediatric Association revised the infant feeding recommendations once more, suggesting that gluten should be introduced in small amounts from 4 months of age and preferably along with on-going breast-feeding. During the epidemic period, the incidence rate of CD children detected clinically under the age of 2 years increased four-fold in comparison to the time period before (pre-epidemic period) and after (post-epidemic period) (Namatovu 2014). A plethora of studies indicates that the incidence rate 
of pediatric CD increased during the latest years, varying though worldwide (Ludvigsson $2013 \mathrm{a}$, Whyte 2013, Zingone 2015).

\section{CD, BREASTFEEDING AND GLUTEN INTRODUCTION}

Previous observational studies in unselected populations suggested that concomitant gluten introduction and breastfeeding should protect at least from early début of CD (Auricchio 1983, Greco 1985, Fälth-Magnusson 1996, Ivarsson 2002). More recent randomized studies in high-risk infants have questioned those results (Vriezinga 2014, Andrén-Aronsson 2014, Lionetti 2014, Szajewska 2015).

\section{DIAGNOSIS}

\section{Serology}

Since the 1980s, serological markers indicative of CD have been developed and become useful tools in the diagnosis of the disease. Moreover, the assessment of antibodies towards gliadin and some auto-antigens empowered the follow-up of patients consuming GFD in terms of compliance to the diet. Antibody testing also enabled screening of populations at risk developing CD, e.g. first-degree relatives, patients with diabetes type 1 etc. (Rostom 2005).

The first antibody used in clinical praxis was the anti-gliadin antibody (AGA) considered to be a revolution in the diagnostic procedure of CD (Volta 1984). The possibility to screen with this serum antibody lead to a considerable change in the concept of celiac prevalence in adulthood, with a prevalence of 1:256 in healthy blood donours, observed in the same catchment area as studied in this thesis (Grodzinzky 1992). AGA are measured by quantitative enzyme-linked immunosorbent assay (ELISA) (Rostami 1999). IgG and/or IgA antibodies towards deamidated gliadin (DGP) peptides can be used as additional tests though, when the other CD serological markers are negative and the clinical picture suggests CD (Prause 2009, Husby 2012). 
IgG antibodies to DGP have the same sensitivity as the IgA but higher specificity. In young children, i.e. less than two years of age, antibodies against DGP appear before antibodies to tissue transglutaminase (t-TGA) and can be considered a useful test when the other tests are negative (Husby 2012). In cases of patients with IgA-deficiency, IgG antibodies to DGP can be tested as a complement to antibodies to t-TGA (Olén 2012). The sensitivity and specificity of IgA and IgG towards DGP varies (Giersiepen 2012) (Table 1).

CD patients also demonstrate elevated antibodies against endomysium (EMA), a connective tissue protein of smooth muscle fibres. EMA are detected using immunofluorescence with monkey or human umbilical cord as substrate (Chorzelski 1983, Ladinser 1994). IgA antibodies towards EMA have high sensitivity and the highest specificity among all diagnostic tools in CD. IgA EMA can be used together with IgA against t-TGA as the first diagnostic tool when investigating patients under the suspicion of CD (Giersiepen 2012) (Table 1). IgG EMA can be tested when IgA-deficiency is present (Husby 2012). Disadvantages of this test are the timeconsuming analysis, the increased cost, and the subjective interpretation of the immunofluorescence leading to variable results in different laboratories (Murray 1997).

In 1997, the autoantigen in endomysium was identified as tissue transglutaminase (Dieterich 1997). This is an enzyme located both intra- and extracellularly in many tissues and organs in the body, e.g. in the intestine. One role of tissue transglutaminase is to perform a targeted deamidation of gliadin that results in higher affinity to the HLA DQ2/DQ8 molecules (Sollid 2002). t-TGA in CD are detected with ELISA assay using guinea pig-, or human recombinant tissue transglutaminase as antigen. The method is quantitative, with less subjective interpretation as compared to EMA analysis, and lower cost (Wong 2002, Wolters 2002). IgG t-TGA can be used in cases of IgA-deficiency (Husby 2012). Antibodies towards tissue tranglutaminase have higher sensitivity in comparison to those towards endomysium (Giersiepen 2012, Olén 2012). 
Table 1. Performance of some serologic tests in pediatric celiac disease (Giersiepen 2012)

\begin{tabular}{|l|c|c|}
\hline Serological test & Sensitivity range & Specificity range $^{2}$ \\
\hline DGP IgA & $80.7 \%-95.1 \%$ & $86.3 \%-93.1 \%$ \\
\hline DGP IgG & $80.1 \%-98.6 \%$ & $86.0 \%-96.9 \%$ \\
\hline EMA IgA & $82.6 \%-100 \%$ & $94.7 \%-100 \%$ \\
\hline t-TGA IgA & $73.9 \%-100 \%$ & $77.8 \%-100 \%$ \\
\hline t-TGA IgG & $12.6 \%-99.3 \%$ & $86.3 \%-100 \%$ \\
\hline
\end{tabular}

${ }^{1}$ Sensitivity: probability that the test will be positive when the disease is present

${ }^{2}$ Specificity: probability that the test will be negative when the disease is not present

\section{Diagnostic criteria}

A small intestinal biopsy was considered the gold standard for CD diagnosis in Europe in the guidelines by ESPGHAN from 1969 (Meeuwisse 1970). The characteristic changes of the small intestinal musosa should be present in the first diagnostic biopsy. Two more biopsies were required in order to fully verify the diagnosis causing the recommendation of a life-long diet with GFD. The second biopsy was performed usually after one year on GFD. If that biopsy revealed a normalised mucosa, the patient should undergo a gluten challenge. Deterioration of the small intestinal mucosa within a time limit of two years of challenge should confirm the diagnosis. If no relapse of the morphological mucosal changes occurred during these two years, the condition was called transient gluten intolerance (TGI). The TGI term was gradually abandoned since the diagnostic criteria based on three different biopsies are no longer in use (Ludvigsson 2013 b).

In 1990, ESPGHAN revised the criteria regarding CD diagnosis suggesting an initial assessment of the small intestinal mucosa showing histopathology consistent with the disease. A clinical and serological response after excluding gluten was necessary for making the correct diagnosis (Walker-Smith 1990).

As described above, the CD diagnosis in Europe was hinged on a small bowel biopsy (SBB) until 2012, when new pediatric guidelines from ESPGHAN advocated a non-biopsy based 
verification of the disease under specific circumstances. Husby et al. suggested that pediatric patients could be diagnosed with $\mathrm{CD}$ when all the following criteria were fulfilled: glutendependent symptoms, positive serology (t-TGA antibody titers $>10$ times the upper limit of normal), and positivity for HLA DQ2 or DQ8 haplotype (Husby 2012).

\section{Small intestinal biopsy}

CD suspicion can be based either on clinical and serological grounds but as described above, until 2012 the gold standard for diagnosing the disease was a SBB (Hill 2005, Stenhammar 2006, Husby 2012). The biopsy can be performed either as upper endoscopy or by a capsule biopsy under fluoroscopic guidance. The second one is nowadays used in Sweden sporadically due to its disadvantages, e.g. risk for radiation exposure (Persliden 1996). At least four mucosal specimens shall be obtained from the second/third portion of the duodenum and one from the duodenal bulb.

Endoscopy has the advantage of collecting multiple specimens and reducing the risk of sampling error in cases of mucosal patchiness (Bonamico 2004). Mucosal alterations in CD can be confined solely at bulbus duodeni (Kappinen 2004, Bonamico 2008). The visual examination and assessment of histological samples from this particular intestinal part with endoscopy allows the detection of such cases.

\section{Histopathology}

The classical histopathological characteristics of CD enteropathy are villous atrophy, crypt hyperplasia and increased intraepithelial lymphocytes. During the last four decades three different grading systems for histological classification of CD mucosal enteropathy has been used in Sweden: the Alexander, the Marsh, and the Swedish KVAST assessment. Alexander (Alexander 1975) described for the first time small intestinal alterations seen in patients with 
Dermatitis herpetiformis, a dermatological disease considered to be a skin variant of CD. He included in his classification four grades of histological deterioration, but did not take into account the intraepithelial lymphocytosis (Table 2).

Table 2. Histological classification of small intestinal biopsies according to Alexander

\begin{tabular}{|l|l|}
\hline Grade & $\begin{array}{l}\text { Steromicroscopic and histological charac- } \\
\text { teristics of the mucosa }\end{array}$ \\
\hline I & $\begin{array}{l}\text { Villi long, narrow, finger like; normal } \\
\text { mucosa }\end{array}$ \\
\hline II & Broad, fused villi; ridged mucosa \\
\hline III & $\begin{array}{l}\text { Broad, short villi; convulted mucosa; partial } \\
\text { atrophy }\end{array}$ \\
\hline IV & No villi, flat mucosa, subtotal villous atrophy \\
\hline
\end{tabular}

The KVAST grading has been used in Sweden the last years as a histopathological classification method of CD (Table 3) (Ludvigsson 2009). It was developed by a Swedish working group of pathologists, called KVAST-group of gastrointestinal pathology. The KVAST classification has been well described and takes into account the intraepithelial infiltration in comparison to Alexander classification.

Table 3. Histological classification of small intestinal biopsies according to KVAST

\begin{tabular}{lcccc}
\hline & Villous atrophy & IEL & $\begin{array}{c}\text { Cell infiltration in } \\
\text { lamina propria }\end{array}$ & $\begin{array}{c}\text { Mitotic frequency } \\
\text { in crypts }\end{array}$ \\
\hline Normal mucosa & - & - & - & - \\
$\begin{array}{l}\text { Borderline } \\
\text { Mucosa }\end{array}$ & - & + & $-/(+)$ & - \\
$\begin{array}{l}\text { Partial villous } \\
\text { atrophy }\end{array}$ & + & + & + & + \\
$\begin{array}{l}\text { Subtotal/total } \\
\text { villous atrophy }\end{array}$ & ++ & + & + & ++ \\
\hline
\end{tabular}

$\mathrm{IEL}=$ intraepithelial lymphocytes $;-=$ normal $;+=$ mild change; $++=$ marked change 
In 1992, Marsh described a progressive sequence of histological alterations resulting finally in villous atrophy (Marsh 1992) (Figure 2). Marsh grading is the most commonly applied nowadays (Table 4). The classification includes five types and also credits the cell infiltration.

Table 4. Histological classification of small intestinal biopsies according to Marsh

\begin{tabular}{lll}
\hline Type & & Histological morphology \\
\hline 0 & Preinfiltrative & Normal \\
1 & Infiltrative & $\begin{array}{l}\text { Normal villous architecture; normal crypt depth; } \\
\text { IEL increase }>30 \text { IEL per } 100 \text { enterocytes }\end{array}$ \\
2 & Hyperplastic & $\begin{array}{l}\text { Normal villous architecture; crypt hyperplasia; } \\
\text { IEL increase }>30 \text { IEL per } 100 \text { enterocytes }\end{array}$ \\
3 & Destructive & $\begin{array}{l}\text { Villous atrophy; crypt hyperplasia; IEL increase } \\
\text { >30 IEL per 100 enterocytes }\end{array}$ \\
& & Partial villous atrophy with minor villous blunting \\
& a* & $\begin{array}{l}\text { Subtotal villous atrophy with moderate villous } \\
\text { blunting }\end{array}$ \\
& b* & Total villous atrophy, i.e. no visible villi \\
& & Villous atrophy; normal crypt depth; normal IEL \\
& counts
\end{tabular}

* three subgroups with different degree of villous atrophy have been suggested for the type 3 lesion by Oberhuber et al. in 1999 (Oberhuber 1999)

** the hypoplastic lesion is considered an irreversible stage and it is very rare 


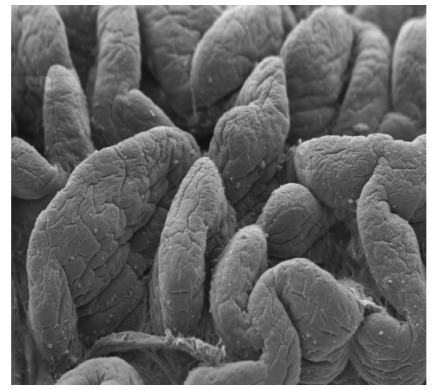

a)

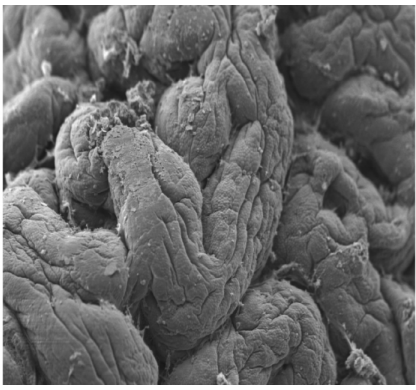

b)

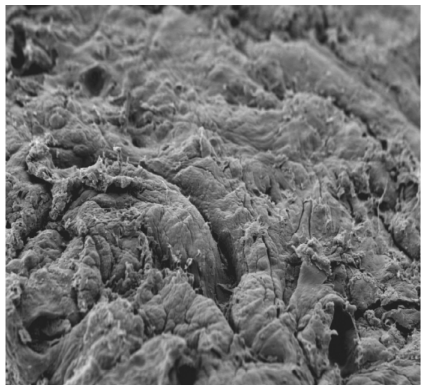

c)

Figure 2. a) normal mucosa showing fingerlike projections into the intestinal lumen b) hyperplastic mucosa after gluten challenge c) the destructive small intestinal mucosa with no visible villi according to Marsh (images from scanning electron microscope obtained from Elisabet Hollén)

\section{CLINICAL FEATURES AND DEMOGRAPHICS}

Initially, $\mathrm{CD}$ was considered solely a pediatric disease but it is now recognised that it can make its début throughout life (Horwitz 2015, Leja 2015). Demographic data present a female dominance among CD patients (McGowan 2009, Ågardh 2015). In the mid 1990s, the mean age at diagnosis was less than two years of age (Ivarsson 2000, Ludvigsson 2004). Various studies from North America, Sweden, and Finland reveal a tendency toward a higher age at diagnosis in recent years, varying from 6.7 to 9.3 years (Mc Gowan 2009, Savilahti 2010, Tanpowpong 2012). On the contrary, the age at diagnosis remains low, i.e. 2.3-3 years of age, in some countries such as Estonia and Spain (Ress 2012, Cillerruelo 2014).

In 2013 the Oslo definitions for CD were published encouraging clinicians to use the following terms: classical $\mathrm{CD}$, non-classical $\mathrm{CD}$ and asymptomatic $\mathrm{CD}$ instead of typical, atypical, and silent, as the latter descriptions were considered vague in many cases (Ludvigsson $2013 \mathrm{~b}$ ).

The group classical CD is represented by patients with symptoms and signs suggestive of malabsorption. Chronic diarrhoea, steatorrhoea, weight loss, growth failure, muscle wasting, iron-deficiency anemia, hypoalbuminemia, vitamin deficiency, poor appetite, protruding ab- 
domen, are often detected in this form of CD (Fasano 2005 a, Fasano 2005 b, Ludvisson 2013 b). The vast majority of these symptoms are mainly seen in young children (Zawahir 2009, Lionetti 2011). In the non-classical form of $\mathrm{CD}$, patients do not suffer from malabsorption. The non-classical symptoms include recurrent abdominal pain, constipation, and extra-intestinal symptoms such as hypertransaminasemia, alopecia, ataxia, epilepsy, and dental enamel hypoplasia. Older children and adolescents more often complain of this kind of symptoms (Ciclitira 2005, Ludvigsson 2013 b). The extra-intestinal symptoms can derive from any organ or body system as a sole sign of CD or occur with concomitant classical symptoms (Lionetti 2011).

Branski et al. reported that the number of patients with only one presenting symptom increased in recent years (Branski 2005). Patients with monosymptomatic disease other than diarrhoea/ steatorrhoea usually suffer fron the non-classical type of CD (Ludvigsson 2013 b).

Screening studies revealed that many CD cases could be asymptomatic (Csizmadia 1999, Mudler 2005). In Sweden, Myléus et al. reported that the $2 / 3$ of patients in their study group were first diagnosed after screening suggesting that probably those individuals were asymptomatic (Myléus 2009). The absence of symptoms often complicates the diagnosis of the disease as the patients feel well and do not seek health services.

Interestingly, over the past decades reports indicate a change in the clinical pattern at the point of CD diagnosis. Studies from Finland (Mäki 1988, Savilahti 2000), Sweden (Ludvigsson 2004), and UK (Ravikumara 2006, Rodrigues 2008) confirmed that children tend to present with more subtle, diffuse and mild symptoms.

\section{HIGH-RISK GROUPS}

The risk for $\mathrm{CD}$ is higher in certain groups of individuals in comparison to the general population. These are, e.g. first-degree relatives, patients with Down's and Turner's syndrome, children with Dermatitis herpetiformis, IgA-deficiency, and autoimmune diseases. Regarding the 
latter group the association with $\mathrm{CD}$ is more evident for diabetes type 1 and autoimmune thyroid disease, but has also been reported for rheumatoid arthritis, Addison's disease, autoimmune hepatitis, and Sjögrens's syndrome (Gasbarrini 2014, Samasca 2014, Ludvisson 2015, Anania 2015). No causal association has however been found between those diseases and CD.

\section{GLUTEN}

The protein composite found in wheat and related grains, including rye, barley and oats are collectively called gluten. Gluten is a cohesive, viscoelastic mass being extracted from wheat flour dough after washing out water-soluble components and removal of the bulk of the starch as well as the cell-wall material. The baking quality of wheat flour is attributed to its cohesiveness (Lamacchia 2014). The alcohol-soluble gluten proteins are called prolamines and the alcohol-insoluble glutenins. Prolamines in wheat are named gliadins, in rye secalins, in barley hordeins and in oats avenins. Prolamines include a high content of the amino acids proline and glutamine (Theethira 2015). The richness in proline and glutamine amino acids confers an unusual resistance to gastrointestinal enzymes and render prolamines a good substrate for tissue transglutaminase, both fenomena favoring the reactivity with mucosal CD4+ cells (Shan 2002, Vader 2002). Oats, in comparison to other cereals, contain less amounts of proline and glutamine amino acids.

Wheat, barley, and rye bear a close taxonomic relationship, whereas oats are taxonomically dissimilar (Figure 3). Avenins, the prolamines of oats, account for $5-15 \%$ of the total seed protein content in comparison to wheat where gliadins represent almost $40 \%$ of the proteins (Vader 2003). 
SUBFAMILY
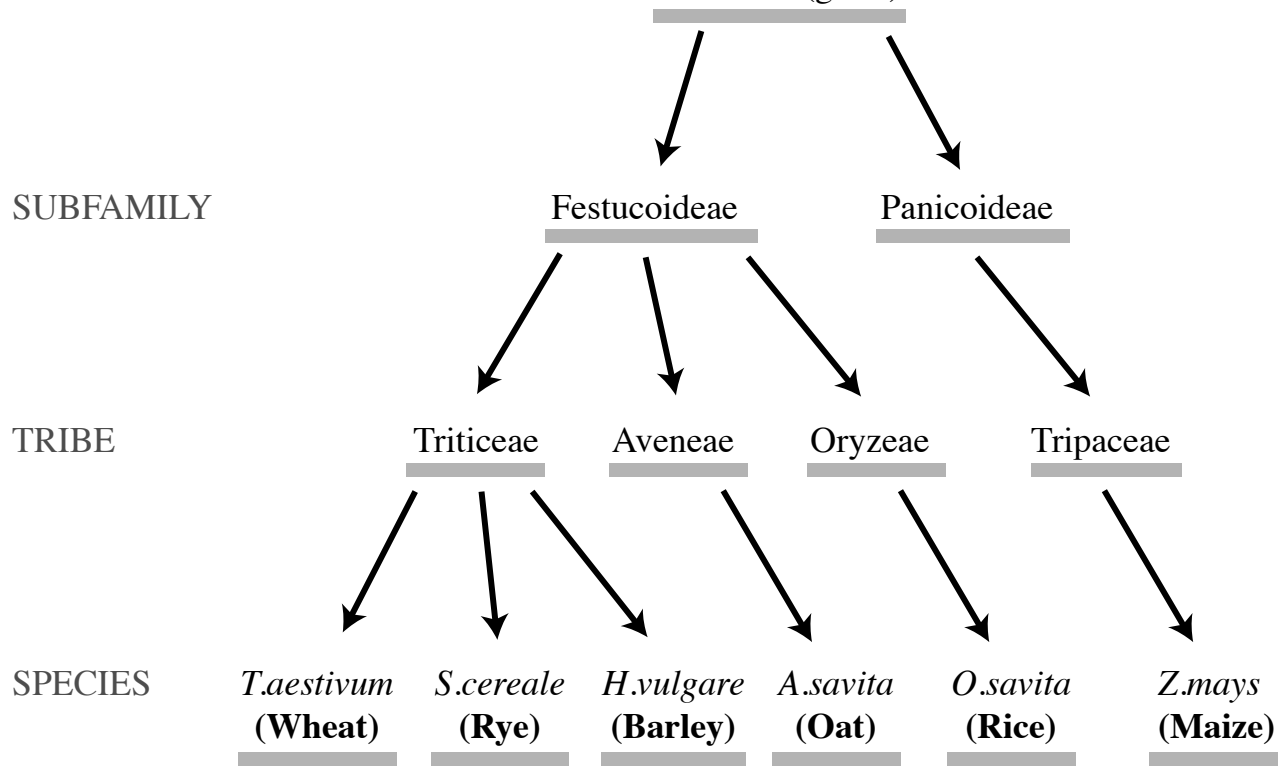

Figure 3. Taxinomic reletionships of some cerials in the grass family, based on Kasarda 1996

The gluten content in some wheat grains used for baking in the ancient times has been investigated and found to be low compared to the modern ones, suggesting that wheat cultivars were less harmful back then (Molberg 2005).

\section{TREATMENT}

\section{GFD: now and then- Oats}

A strict, lifelong GFD is the only recommended treatment in CD (Veeraraghavan 2015). During the years, non-dietary treatments were investigated but the results were discouraging (Sollid 2011, Plugis 2015, Dielli-Crimi 2015). GFD meant initially abstention from wheat, barley, rye and oats. It is unavoidable that even the gluten-free products, pre-packaged and natural, can include residual amounts of gluten (Størsrud 2003 a). This pinpoints the importance of determining 
the upper limit of gluten amounts in the gluten-free products consumed by the patients. Both in North America and Europe the threshold for gluten contamination is established at 20 parts per million (ppm) in given gluten-free food (La Vieille 2014). Daily consumption of gluten up to $10 \mathrm{mg}$ does not lead to mucosal alterations (Catassi 2007, Akobeng 2008). However, it should be acknowledged that the individual sensitivity differs significantly (Laurin 2002).

The putative inclusion of oats in the diet has been a controversy for many years. Numerous studies during the last decades, first on adults and later on children, suggested that oats grown, processed and packed entirely separated from cereals containing gluten, have no unfavorable effects and can safely be part of the GFD. In 1995, Janatuinen et al., reported that daily consumption by adults of moderate amounts of oats, i.e. $50 \mathrm{gr}$, did not cause any adverse effects (Janatuinen 1995). Five years later, the same cohort was followed-up showing no signs of relapse in their CD after a daily mean consumption of $30 \mathrm{gr}$ of oats (Janatuinen 2002). Many studies followed, suggesting that oats both in moderate (Shrinivasan 1996, Peräaho 2004, Thies 2014) but also in large amounts can be a part of the GFD (Størsrud 2003 a).

Högberg et al. performed a randomised, double blinded study on children consuming a mean amount of 15 gr oats daily during a one-year period. The patients were monitored with serological testing for CD and had undergone a SBB at the end of the study period. The results of the study suggested that addition of oats in the GFD did not jeopardize clinical or mucosal recovery (Högberg 2004). Oats supplementation in the GFD of Swedish pediatric population was recommended by the Swedish Pediatric Association in 2004 (Stenhammar 2004). Two years later a Finnish controlled trial of children consuming oats (median amount of $45 \mathrm{gr} /$ day) for two years, did not reveal any signs of mucosal alteration in the SBBs. At the end of the study the serological markers were also normalised, and remained so after an extended follow up to 7 years (median; 5 years), suggesting that oats should be well tolerated by the pediatric population (Holm 2006). 
Koskinen et al. reported that oats did not induce transglutaminase autoantibody production at the mucosal level on pediatric patients consuming oats for a period of 2 years (Koskinen 2009). Some in vitro studies also support that oats addition in the GFD is safe. Picarelli et al. suggested that the immunogenic sequences that were found in gliadin, inducing a Th1 response, were not present in avenin (Picarelli 2001). Kilamartin et al, showed that in vitro challenge with avenin did not induce production of EMA (Kilamartin 2003). Additionally, Londono et al., has recently investigated the presence of known immunogenic peptides from wheat, rye, and barley in the whole genus Avena (oats). Such peptides were though not present, suggesting that oats should be safe for CD patients (Landono 2013).

On the contrary, Arentz-Hansen et al. and Lundin et al., suggested that the presence of avenin-reactive T-cells in the mucosa of patients who have been consuming oats could have resulted in mucosal inflammation (Lundin 2003, Arentz- Hansen 2004). Other studies imply that cross-reactivity between avenin and gluten at T-cell clonal level, could possibly explain the adverse reactions (Vader 2003). Excretion of NO metabolites in the urine of untreated patients with $\mathrm{CD}$ has been suggested to be a strong indication of an ongoing small intestinal inflammation (Sundqvist 1998). Our group has previously shown that almost $2 / 3$ of children with CD on an oats-containing GFD during one-year period, demonstrated the same reduction in urinary NO metabolites as the children consuming a traditional GFD did. However, 1/3 did not show a similar reduction indicating that a long-term follow-up of oats consumption is needed (Hollén 2006).

Wheat-starch inclusion in the GFD has also been discussed during the past years. Several studies indicated that starch is safe to use in the diet (Lohiniemi 2000, Peräaho 2003).

Oats are beneficial for CD patients in many aspects. They constitute a rich source of the vitamin B-group, minerals and proteins. They also contain antioxidants and have a high soluble 
fiber content (Richman 2011, Clemens 2014). Inclusion of oats in the GFD gives food diversity and improves compliance to the GFD (Størsrud 2003a, Størsrud S 2003b).

\section{GFD compliance}

Many studies have tried to elucidate the general compliance to the GFD in pediatric populations and the results varied between 30-95\% (Jackson 1985, Kumar 1988, Mayer 1991, Ljungman 1993, Mariani 1998, Tommassini 2004, Rashid 2005).

Compliance assessment can be achieved through serological tests, self-reporting methods, i.e. interviews and questionnaires, and multimodel approaches, e.g. combination of serology and questionnaires.

The lack of agreement whether EMA and t-TGA are reliable markers for CD monitoring is due to the fact that cases of occasional non-adherence can be missed since the antibodies can be normal. However, they are useful methods, detecting patients with low adherence to diet, gluten consumption on regular basis, and exposure to gluten during a longer period (Fabiani 2000, Tommassini 2004, Hommel 2008).

In self-reporting methods, the subjective nature of the answers and the risk for recall bias combined with children's fear of admitting possible dietetic transgressions can be considered as drawbacks of this type of investigations. On the contrary, they are considered feasible, noninvasive ways of monitoring patients with chronic diseases (Hommel 2008).

Patients compliant with the GFD experience a plethora of benefits: rapid remission of clinical symptoms, weight improvement, better quality of life and psychological well-being for the symptomatic patients, better mood, and increased school performance (Gheller-Rigoni 2004, Newnham 2015). Studies concerning asymptomatic or screening detected patients reported various outcomes: positive or no effects of the GFD in the quality of life of CD patients (Mustalahti 2002, Johnston 2004, Nachman 2008). 
Various barriers for achieving compliance have been reported in the literature. Issues of availability have been discussed. Finding strict GFD at social occasions outside home, i.e. at dining, travelling and being guest at other homes, discourages patients in complying with the diet. The increased cost of the gluten-free products and mislabelling of food claimed to be gluten-free are obstacles that CD patients have to overcome and these factors may influence the compliance to the diet (Pietzak 2005, Mc Culloch 2014). Psychological stress was also described as an inconvenience affecting compliance, as friends and classmates could shun them because of their GFD (Byström 2012).

Some studies suggest that compliance among individuals diagnosed with $\mathrm{CD}$ during adolescence or through screening is low (Fabiani 2000, Högberg 2003), whereas a Swedish study found good dietary compliance among those screening-diagnosed adolescents (Webb 2015). Mc Culloch et al. did not find significant compliance discrepancies between the two sexes or among children with varying disease duration, but reported that adolescents had significantly lower adherence compared to younger children, reported by their caregivers. This could be explained by possibly "embellished" reports from the parents compared with self report given directly by the patients (Mc Culloch 2014).

\section{GENETICS}

Genes encoding for the human leucocyte antigen (HLA)-DQ2 and DQ8 are located on chromosome 6 and confer risk for CD (Dieterich 2003). The HLA-DQ2 and/or DQ8 molecules are present in the vast majority of CD patients $(95 \%)$, but also in $35 \%$ of the general population, implying that HLA is not a sufficient factor for the pathogenesis of the disease, making the positive predictive value poor (Karell 2003, Hadithi 2007, Wijmenga 2014). Patients negative for HLA DQ2/8 are not in need of repeated testing for CD antibodies because of its high negative predictive value (Karell 2003). Concordance among HLA identical siblings is estimated to $30 \%$ 
while it increases up to $70 \%$ in monozygotic twins. The two HLA genes do not contribute more than $40 \%$ to the familial risk for CD development (Bevan 1999).

Additionally, the genetic predisposition of the disease encompasses even non-HLA associated genes, i.e. 40 different loci detected through genome-wide association studies (GWAS) (Dieterich 2003, van Heel 2007, Wijmenga 2014). Most of them contain genes that control the adaptive immune response (Hunt 2008). Romanos et al. showed that a model, combining HLA and 57 non-HLA genes in comparison to HLA alone, resulted in decreased positive predictive value, from $94 \%$ to $57 \%$, although sensitivity increased (Romanos 2014).

\section{PATHOGENESIS}

$\mathrm{CD}$ is considered an autoimmune disease where the innate and adaptive immune systems are being involved. Gluten peptides from wheat (gliadin), rye (secalin), and barley (hordein) pass through the small intestinal epithelial cell layer reaching lamina propria (Alaedini 2005). This occurs in two ways; a) through leaky intercellular tight junctions but also b) transcellulary (Fasano 2008). Gliadins, secalins, and hordeins are peptides rich in the amino acids proline and glutamine, so called prolamines. After entering the lamina propria, these peptides are deamidated by the enzyme tissue transglutaminase charging them negatively and increasing their affinity for HLA DQ2 and DQ8 molecules. After being bound to those receptors on antigen presenting cells, e.g. dendritic cells, macrophages, they are presented to CD4+ T-cells (Molberg 1998, Sollid 2002, Kagnoff 2005, Fasano 2012, Di Sabatino 2015).

The activation of gluten-specific T-cells leads to an inflammatory response including production of pro-inflammatory cytokines, especially interferon $\gamma$, and chemokines leading initially to infiltration of IEL in the small intestinal mucosa and gradually to deterioration of crypts and villi (Hansson 1999, Björck 2015). Clonal expansion of B-cells yields production of antibodies, i.e. AGA, EMA and t-TGA (du Pré 2015). 


\section{NITRIC OXIDE}

$\mathrm{NO}$ is a free radical regulating cellular signaling and orchestrating a wide variety of functions in the human body. NO is involved in physiological and pathological processes (Hou 1999). Production of NO in balanced concentrations influences the vascular dilatation, neurotransmission, and various immune responses (Änggård 1994, Wallace 2000, Daniels 2005).

In the gastrointestinal tract, NO seems to have a dual effect. Low concentrations of NO can improve the mucosal integrity, while exaggerated amounts could lead to severe tissue damage after the production of oxidative substances (Kubes 1992, Villarreal 1995, Rachmilewitz 1995).

NO derives from the amino-acid L-arginine in a reaction catalysed by a family of enzymes called nitric oxide synthases (NOS). To date three distinct isoforms of NOS have been described in mammals, two constitutive (cNOS) and one inducible (iNOS). These three isoforms have diverse functions and are detected in different tissues of the body. The two cNOS are

$\mathrm{Ca}^{2+}$-dependent and produce nanomolar amounts of NO in short bursts. They are expressed in neuronal (nNOS) and endothelial cells (eNOS). The third isoform, iNOS, is calciumindependent, producing micromolar quantities of NO continously. iNOS are expressed in various cells such as macrophages, neutrophils, smooth muscle cells, and endothelial cells in response to different pro-inflammatory cytokines (Änggård 1994, Moshage 1997, Wallace 2000).

NO is labile and is oxidised to the metabolites nitrite and nitrate which are excreted in the urine.

Studies have showed elevated levels of NO metabolites in the urine of children with untreated CD (Sundqvist 1998, van Straaten 2003). Our, as well as other groups, have previously found that these marked levels of NO metabolites were due to an increased activation and expression of iNOS in the small intestinal mucosa (Holmgren-Peterson 1998, Murray 2002, Daniels 2005). NO metabolites though decreased in $2 / 3$ of the cases after consumption of oats-including GFD during a one-year period (Hollén 2006). 
Besides being endogenously produced, the NO metabolites are however abundant in our everyday diet, e.g. smoked food, spinach, and beetroot, and that could possibly have impact on the levels in the urine, blood and saliva (Gangolli 1994, Ximenes 2000, Larsen 2014). Drinking water could also contain considerable amounts of nitrate but in many countries these levels are strictly regulated (Lundberg 2008).

It has also been suggested that urinary tract infections, renal insufficiency, rheumatoid arthritis and active inflammatory bowel disease lead to increased excretion of NO metabolites in the urine (Grabowsky 1996, Goggins 2001, White 2011). Increased urinary levels can also be caused by Rotavirus gastroenteritis, septicemia, and even asthma in children (Ciuk 2001, Rodríguez-Díaz 2006, Aranke 2011).

The plasma and urinary levels of NO metabolites, such as nitrite and nitrate, reflect the total production of NO in the body (Weinberg 2006). The ratio of urinary excreted nitrite/nitrate represents 50 to $60 \%$ of the total body clearance of these compounds, while the remaining amounts are being eliminated by the exocrine glands, the respiratory, and the gastrointestinal tract (Weinberg 2006). The half-time of nitrate in plasma is almost 5 to 6 hours and under ordinary conditions NO metabolites are rapidly excreted into urine (Lundberg 2008). The measurement of urinary NO metabolites is considered to be reliable when the urine samples are stored at $4{ }^{\circ} \mathrm{C}$ in order to avoid bacterial growth and secondarily increased nitrite production (Bories 1995). Fasting for 12 hours is reported to reduce $54 \%$ of plasma concentrations of nitrate. In healthy fasted individuals almost 90\% of plasma nitrate derives from NOS (Rhodes 1995). 


\section{AIMS OF THESIS}

The overall aim of this thesis is to study how pediatric CD has changed during a 41-year period in Sweden in terms of clinical presentation, incidence, and demographics. We also wanted to discuss the compliance to the GFD and safety of using oats in the diet.

The objectives were to:

\section{Paper I:}

$\checkmark$ investigate possible changes in mean age at diagnosis, disease severity in terms of pathological findings, and clinical presentation pattern of pediatric CD over a 41-year study period.

\section{Paper II:}

$\checkmark$ address whether the incidence of pediatric CD in a Swedish region continued to be very high.

$\checkmark$ assess if the diagnostic activity and accuracy had increased after the introduction of new screening methods, i.e. various serological tests.

$\checkmark$ elucidate how cases with mild enteropathy were clinically evaluated between 1973 and 2013.

\section{Paper III:}

$\checkmark$ study the compliance with GFD among CD children.

$\checkmark$ explore the use of oats in the GFD and their safety after a long-term consumption.

$\checkmark$ deepen the knowledge of the dietary habits of celiac children. 


\section{Paper IV:}

$\checkmark$ elucidate the effects of purified oats on the concentration of urinary NO metabolites in celiac children who had been on an oats-containing GFD over one-year period.

$\checkmark$ address possible effects of nitrite/nitrate-containing foods on the urinary concentrations of NO metabolites. 


\section{METHODS}

\section{POPULATION AND CATCHMENT AREA (paper I, II, III, IV)}

The studies included patients who resided in the County of Östergötland, a defined geographical area in southeast Sweden. The catchment area of the county is about 450,000 inhabitants, representing almost $5 \%$ of the national population (January 1, 2014). Children up to 18 years of age amount to $20 \%$ of the local population. The county is served by three pediatric clinics, in Linköping, Motala, and Norrköping. In paper III and IV patients from the neighboring city of Västervik were included in the respective studies. All the population data derived from the Swedish Central Bureau of Statistics.

\section{LOCAL CD DATA COLLECTION (paper I, II)}

In 1973 pediatricians in the county launched a local database including children who were investigated under the suspicion of $\mathrm{CD}$. Information about age at diagnosis, sex, clinical symptoms and the results of biopsy examination was prospectively added in the database between 1973 and 2013. The analyses of the filed data were performed in 2014 and 2015, when some original charts $(n=145)$ were re-examined in the case of missing or incomplete information.

\section{SUBJECTS}

\section{Paper I}

This cohort study comprised 1030 pediatric patients, diagnosed with CD between 1973 and 2013. Among them, 987 received a biopsy-confirmed diagnosis and 43 were diagnosed according to the revised ESPGHAN criteria without SBB (Husby 2012). Detailed biopsy reports 
were available for $99.8 \%$ of the patients and information about age at diagnosis and clinical picture during the disease début was also accessible. The age at diagnosis was defined as the age at first biopsy although the definite diagnosis came later, according to ESPGHAN criteria. Those diagnosed without SBB were regarded as celiacs when all the serological results were presented.

\section{Paper II}

This cohort study identified all children investigated for suspected CD between 1973 and 2013 in the county. In this 41-year study period, 2,790 patients could be included in the final study analysis while 66 were excluded due to various reasons (Figure 4). The subjects were classified into three different groups based on the diagnosis. CD was established in 1,030 patients and among them 987 received a biopsy-confirmed diagnosis, and 43 were diagnosed according to the revised ESPGHAN criteria without SSB. Additionally, 1,732 were categorized as non-CD patients and another 28 were regarded as TGI patients (Figure 4). The trends of incidence rate and cumulative incidence of this cohort during the whole study period were addressed here. It was also a study of the diagnostic activity and accuracy when performing small intestinal biopsies in the investigation for CD. Histopathological evaluations were complete in $99.9 \%$ of the cases. 

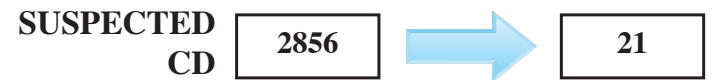

RECORDS NOT FOUND

INVESTIGATION
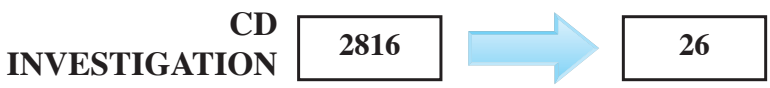

BIOPSY FAILED

19 $>18$ YEARS OLD
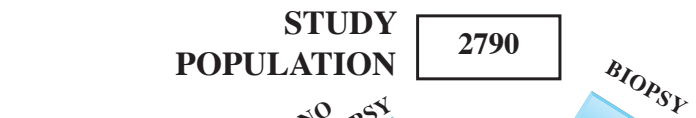

GFD
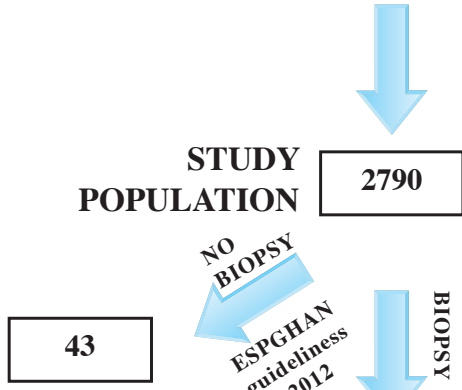

GFD

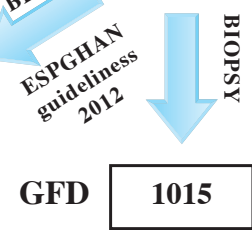

1732

NOT CD

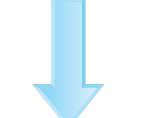

GFD
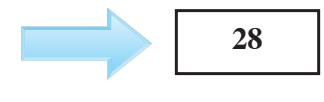

TGI
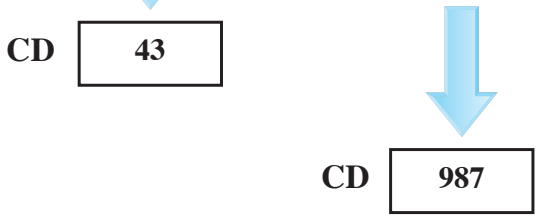

CD

987

Figure 4. Flowchart of investigation.

\section{Paper III}

This is a questionnaire-based study including 316 children and adolescents from four different pediatric clinics in southeast Sweden. Patients included in the study were less than 18.5 years of age, had undergone a SBB showing enteropathy compatible with celiac disease, and were consuming a GFD. 


\section{Paper IV}

In order to investigate the effects of purified oats on the concentration of urinary NO metabolites in children with $\mathrm{CD}$ who had been consuming an oats-containing GFD over a long-term period, 188 individuals were included in the study. They all provided a morning urine sample after an overnight fast and filled in a questionnaire before visiting the outpatient department. The criteria for inclusion in the study were: age less than 18.5 years, a SBB showing enteropathy compatible with $\mathrm{CD}$, and consumption of GFD.

\section{ASSESSMENT OF CLINICAL SYMPTOMS (paper I)}

The study subjects were divided into four groups depending on the presenting symptom of the disease: i) gastrointestinal, ii) extra-intestinal, iii) failure to thrive (FTT) and/or short stature, and iv) no obvious symptoms - detection by screening. The clinical symptoms were assessed with a severity score: no symptoms, i.e. asymptomatic $=1$, moderate symptoms $=2$, severe symptoms $=3$, based on information from the patients and/or their parents. The most intense one characterised the severity in cases of multiple symptoms. Symptoms such as continuous constipation problems, daily abdominal pain, frequent diarrheas per day, low hemoglobin, and/or weight losss cored 3. Children with intermittent diarrheas or constipation, mild abdominal pain were given a score 2 .

\section{QUESTIONNAIRE}

\section{Paper III}

Pediatric dieticians elaborated a food questionnaire used for the annual check-ups of our CD patients. Initially, several pilot versions of the questionnaire were used and evaluated before it was finalised and distributed. Prior to visiting the outpatient departments, the children or the 
parents, in the case of younger patients, were asked to answer the questionnaire. The questions involved various aspects of the GFD, e.g. duration and strictness of the diet; possible mistakes related to gluten consumption; experienced symptoms after accidental ingestion; and other issues related to the GFD. They also addressed inclusion of oats in the diet, the duration and frequency of oats consumption, preferred oats products, and reasons for abstention from oats. An experienced pediatric dietician assessed the amount of accidental gluten intake. Altogether, 316 questionnaires were returned and $95 \%$ of them were correctly and fully completed.

\section{Paper IV}

Before visiting the outpatient departments the children or, in case of younger children, the parents were asked to report, by filling in a questionnaire, the food consumption during the 24 hours preceding the urinary sampling and provide relevant medical history information, e.g. gastrointestinal symptoms (due to e.g. gastroenteritis, inflammatory bowel disease), urinary tract infection and asthma, conditions that could cause increased urinary NO metabolites (Grabowsky 1996, Ciuk 2001, Goggins 2001, Rodríguez-Díaz 2006, White 2011). Before being administered to the CD families, several pilot versions of the questionnaire were tested. It included questions covering consumption of spinach, mango, beetroot and smoked food, i.e. ham, salami and sausage prior to sampling. Those are nitrite/nitrate rich foods and could possibly affect the NO urinary concentrations (Gangolli 1994, Ximenes 2000, Larsen FJ 2014). Other relevant questions were oats inclusion in the GFD, duration of oats consumption, purity of oats ingested and strictness in the adherence to GFD. A total of 188 questionnaires were returned along with a corresponding urinary sample, i.e. sample voided the morning before visiting our outpatient department. 


\section{NITRIC OXIDE MEASUREMENTS (paper IV)}

$\mathrm{NO}$ is oxidised in the body into the inorganic metabolites nitrite $\left(\mathrm{NO}_{2}{ }^{-}\right)$and nitrate $\left(\mathrm{NO}_{3}{ }^{-}\right)$, which are excreted in the urine. Morning urine samples were voided after an overnight fast, in order to minimize possible dietary contribution of urinary NO metabolites (Gangolli 1994, Rhodes 1995, Grabowski 1996, Ximenes 2000, Larsen 2014). Urine was brought to the annual followup at our outpatients department and stored at $-20^{\circ} \mathrm{C}$ until analysed. In the samples, the sum of nitrite and nitrate was regarded as an indirect indicator of the NO production (Weinberg 2006, Lundberg 2008). Thus, the enzyme nitrate reductase from Aspergillus sp., converted nitrate to nitrite in phosphate buffered saline (PBS)-diluted urine sample. This occured by mixing $50 \mu 1$ of the diluted urine with $10 \mu \mathrm{NADPH}(1 \mu \mathrm{M})$ followed by $40 \mu 1$ of a freshly prepared mixture containing nitrate reductase (80U/1, Roche, Basel, Switzerland), glucose-6-phosphate $(500 \mu \mathrm{M})$ and glucose-6-phosphate dehydrogenase (160U/1). The reaction mixture was incubated for 45 minutes at room temperature and then used for the Griess assay of nitrite by adding $100 \mu \mathrm{l}$ sulphanilamide (1\% in 5\% phosphoric acid) and $100 \mu \mathrm{N}$ - (1-napthyl) ethylenediamine $\mathrm{HCl}(0.1 \%)$. The resultant colour was read with a spectrophotometer (Vmax; Molecular Devices, Sunnyvale, Calif, USA) at $540 \mathrm{~nm}$ (Verdon 1995). A cut-off value at $1400 \mu \mathrm{M}$ urinary nitrite was set according to a previous study, in which a group of non-coeliacs was included as reference group. This corresponded to the mean value +2 SEM for the reference group (Sundqvist 1998).

\section{HISTOPATHOLOGICAL EVALUATIONS}

Since the SBB was introduced in the clinical praxis at the pediatric departments of the county in 1973, the Watson capsule was predominantly used. In 1992, Storz capsule came to use until 
the early 2000s when gastroscopy started to gradually replace the capsule technique. Over the 41-year study period, three different grading systems have been used at the pathology department in the county for biopsy classification of the CD enteropathy: the Alexander, the Marsh, and the Swedish KVAST assessment (Alexander 1975, Marsh 1992, Ludvigsson 2009) (Tables 2, 3, 4). For the calculations in this study the material was reclassified as follows: biopsy score 1 if there was normal or almost normal mucosa (Alexander I, Marsh 0, and KVAST normal); biopsy score 2 for mild enteropathy (Alexander II, Marsh I and II, and KVAST borderline); and biopsy score 3 for severe enteropathy (Alexander III and IV, Marsh IIIa, IIIb, and IIIc, and KVAST partial or subtotal/total villous atrophy). Those with Alexander grade III or above, Marsh 3 or above, and KVAST partial or more serious villous atrophy were considered as CD.

\section{Paper I}

From our local patient database $985 / 987$ pathology reports were retrieved, i.e. $99.8 \%$ of the cases with biopsy-based diagnosis. Detailed biopsy reports regarding the severity of mucosal alterations were available for $99.9 \%$ of the patients who had undergone a SBB.

\section{Paper II}

A total of 987 pathology reports were available from the CD group and 1732 from the nonCD group. In 191 cases double evaluations with two different manuals were available.

For $99.9 \%$ of the patients who had undergone a SBB, a complete biopsy report regarding the severity of mucosal alterations was available.

Twenty nine patients were evaluated histologically as Alexander grade II, Marsh I or II, and KVAST borderline, but were still allocated to the CD group after the pediatrician's judgment based on a combination of the following factors: 1) convincing clinical symptoms, 2) in- 
creased levels of IELs in the SBB, 3) increased CD antibody levels and/or 4) inedequate gluten exposure prior the biopsy.

\begin{abstract}
ANTIBODIES
The CD antibody analyses, i.e. AGA, EMA, and t-TGA, were performed at the same laboratory in the county through the study period. AGA was established in the clinical praxis in the mid 1980s and EMA in the mid 1990s (Grodzinsky 1990, Grodzinsky 1994). In 1989 and 1999, respectively, more than $50 \%$ of the children with suspected $\mathrm{CD}$ were investigated with these serological tests in the county. In 2003 t-TGA was included in the clinical routine of CD investigation in more than $50 \%$ of our cases.
\end{abstract}

\title{
DIAGNOSTIC ACTIVITY \& ACCURACY (paper II)
}

Diagnostic activity was defined as the number of children who have undergone a SBB due to suspected CD per 1,000 children below 18 years in the catchment area.

Diagnostic accuracy was determined as the number of pediatric CD cases per total number performed SBB under CD suspicion.

\section{STATISTICAL METHODS}

Analyses were performed using SPSS software (SPSS Statistics for Windows, Version 22.0. and 20.0 IBM Corp., Armonk, NY). A p value $<0.05$ was considered statistically significant.

\section{Paper I}

Frequency comparisons of the presenting symptoms at the different study subperiods and age groups, as well as of the severity of presenting symptoms at the three study periods were performed using the chi-square test. 
Differences between group age means at the three study periods were determined by one-way ANOVA and confirmed by least significant difference (LSD) post hoc tests. Unpaired Student's t-test was used to compare characteristics and means of two different samples i.e. mean age at diagnosis of female and male subjects during the study period.

\section{Paper II}

The chi-square test was used for frequency comparisons of: patients with mild enteropathy evaluated with three different scoring systems, i.e. Alexander II, Marsh 1 and 2, and KVAST borderline; cases of mild enteropathy in $\mathrm{CD}$, non-CD patients, and in the whole study population during three different study periods; as well as when comparing the ratios of sex distribution between $\mathrm{CD}$ and non-CD patients. Differences between group age means of the CD and non-CD patient groups, during three different periods were determined by one-way ANOVA and confirmed by LSD post hoc tests. In case of not normally distributed variables, i.e. means of diagnostic accuracy and activity at the three study periods, the differences between group means were determined by the Kruskal-Wallis test.

\section{Paper III}

The chi-square test and Fisher's exact test were used to analyze differences in frequencies concerning gender, age, duration of GFD, and oats consumption in relation to GFD adherence.

The Spearman rank correlation test was used to calculate correlation between not normally distributed data, i.e. the amount of accidental gluten intake and the time of the début of symptoms. 


\section{Paper IV}

The chi-square test and Fisher's exact test were used to analyse differences in frequencies regarding: a) compliance to GFD, oats consumption, sex, and age in children with celiac disease, between the subgroups with normal and high concentrations of urinary NO metabolites, respectively, and b) consumption of different foods that could possibly affect the levels of NO metabolites in the urine of children with celiac disease

The Spearman rank correlation test was used for calculation of correlation between the duration of oats consumption and concentration of urinary NO metabolites.

\section{ETHICAL CONSIDERATIONS}

The studies in Paper I, II, III, and IV were approved by the Human Research Ethics Committee of the Faculty of Health Sciences, Linköping University, Sweden. All patients were below 18 years of age making the parents their legal representatives, and as such, the parents signed the informed consent. However, a special information sheet was available for the patients/children with ability to read, and those children often co-signed the informed consent to confirm their approval. 


\section{RESULTS \& DISCUSSION}

The main findings of the thesis are presented among others in the following section. Further details are given in Papers I-IV, respectively.

\section{PAPER I}

\section{Age and sex distribution}

The mean age at CD diagnosis in this study group was 6 years (5.7-6.3). A maximum of 9.9 years was observed in 2009. The mean age at diagnosis for the whole study population, and also for the boys and girls subgroups, rose gradually through the 41-year study period (Figure $5)$.
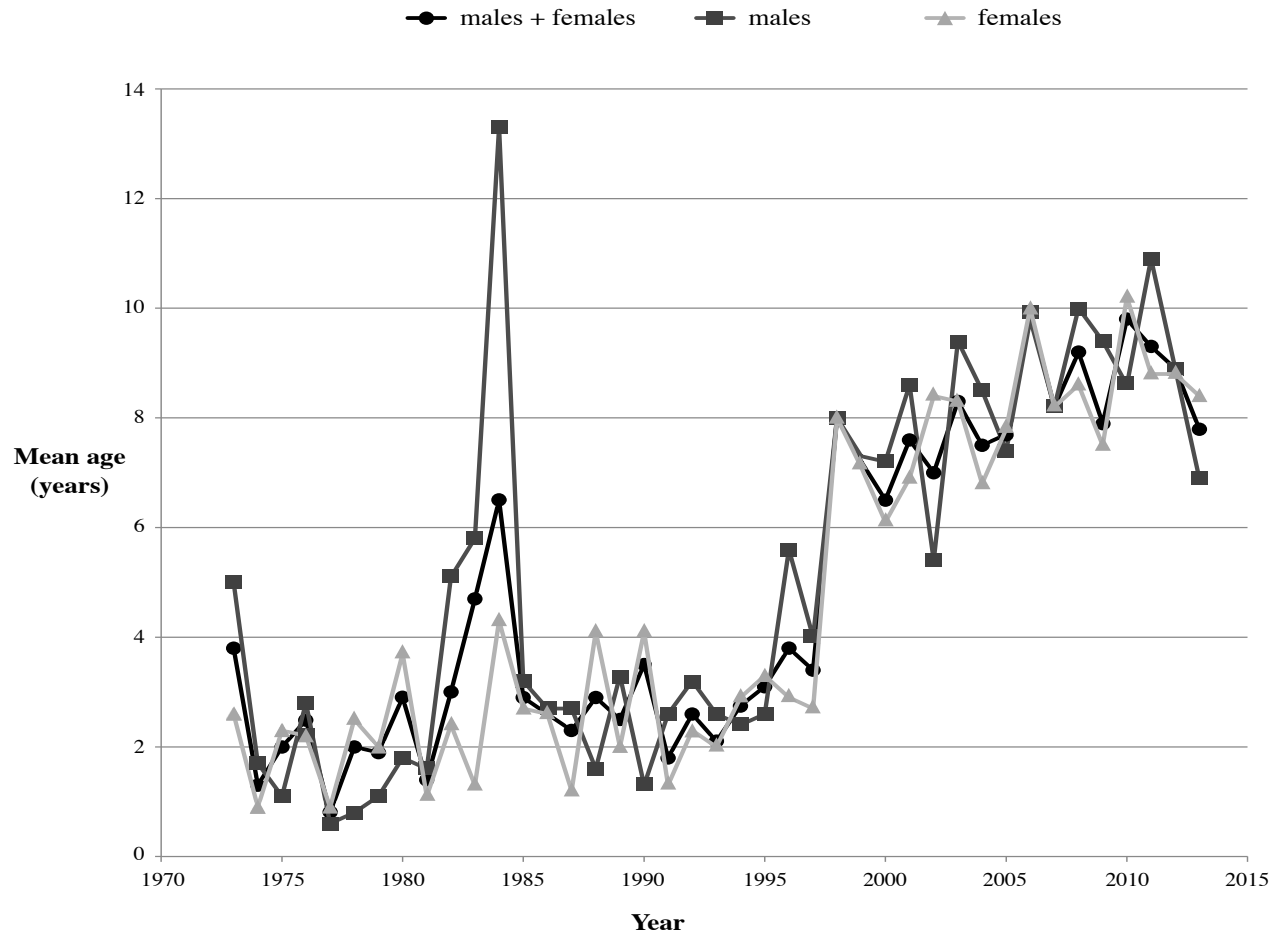

Figure 5. The mean age at $\mathrm{CD}$ diagnosis of the whole study population (black), male (dark grey) and female (light grey) subgroups during the study period (1973-2013) 
The mean age at diagnosis of the study population at the pre-epidemic, epidemic and postepidemic periods were $2.2(1.6-2.8), 2.8$ (2.4-3.2), and 8.2 (7.8-8.6) years, respectively. The male and female populations studied separately displayed similar results as shown in Table 5. A statistically significant increase concerning the age at diagnosis at the post-epidemic period in comparison to the other two periods was noted for all three groups, i.e. the whole population, boys, and girls, when performing post-hoc LSD tests.

Table 5. Mean age of the whole study population, female and male subpopulations during three different study periods, presented as mean age in years $(95 \%$ confidence interval)

\begin{tabular}{lllll}
\hline & Pre-epidemic $^{\mathbf{1}}$ & Epidemic $^{\mathbf{2}}$ & Post-epidemic $^{\mathbf{3}}$ & p value $^{\mathbf{4}}$ \\
\hline Study population & $2.2(1.6-2.8)$ & $2.8(2.4-3.2)$ & $8.2(7.8-8.6)$ & $<0.001$ \\
& $\mathrm{n}=98$ & $\mathrm{n}=319$ & $\mathrm{n}=613$ & \\
Males & $2.4(1.4-3.4)$ & $2.8(2.1-3.5)$ & $8.3(7.6-8.9)$ & $<0.001$ \\
& $\mathrm{n}=39$ & $\mathrm{n}=112$ & $\mathrm{n}=222$ & \\
Females & $2.2(1.5-2.9)$ & $2.7(2.2-3.2)$ & $8.2(7.7-8.8)$ & $<0.001$ \\
& $\mathrm{n}=59$ & $\mathrm{n}=207$ & $\mathrm{n}=391$ & \\
\hline
\end{tabular}

${ }_{2}^{1}$ pre-epidemic period $=1973-1983$

2 epidemic period $=1984-1996$

${ }_{4}^{3}$ post-epidemic period $=1997-2013$

${ }^{4}$ differences in means were tested with 1-way ANOVA test

The boys' mean age at diagnosis during the 41-year study period exceeded that of the girls in 25 out of 41 years $(\mathrm{p}=0.046)$.

Our study clearly demonstrated a significant increase in age at diagnosis of CD children after the epidemic period in Sweden. This result coincides with data reported from other countries but also from Sweden, suggesting similar increase (Mc Gowan 2009, Savilahti 2010, Tanpowpong 2012, Namatovu 2014). It is worth mentioning that the increase of mean age at diagnosis for the neighboring Finnish children preceded the Swedish dito observed after the epidemic period (Ascher 1993). On the contrary, the age at diagnosis remains low, i.e. 2.3-3 years of age in some countries such as Estonia and Spain (Ress 2012, Cillerruelo 2014). Several factors not fur- 
ther studied in this thesis could be responsible for that, i.e. different infant feeding practices, which could influence the age at diagnosis or different genetic background.

The female-to-male distribution in the present study was $1.8: 1$, in line with other studies (Roma 2009, Ress 2012, Fortunato 2014). The sex distributions varied, but not significantly, between different age groups and among the pre-epidemic, epidemic and post-epidemic periods. Tanpowpong et al. could not either show any difference between age groups and sex (Tanpowpong 2015).

\section{Symptoms at presentation}

The gastrointestinal manifestations as a presenting symptom of $\mathrm{CD}$ decreased during the study period ( $82 \%$ pre-epidemic, $68 \%$ epidemic, $71 \%$ post-epidemic), albeit not significantly. They still remain the most common type of symptom through the years and among all age groups. However, these findings differ from those reported from the neighbouring country Finland from the 1980 s and 2000 s, in which only $50 \%$ of the patients had gastrointestinal symptoms (Mäki 1988, Savilahti 2010). On the contrary, significant differences were found between the study periods regarding extra-intestinal symptoms $(\mathrm{p}<0.001)$, FTT with or without short stature $(p<0.001)$, and frequency of patients detected through screening $(p<0.001)$. During the post-epidemic period, extra-intestinal symptoms $(\mathrm{p}<0.001)$ and FTT and/or short stature $(\mathrm{p}<0.001)$ were significantly less common than in the first two periods, whereas patients detected through screening were significantly more common $(p=0.006)$.

In the post-epidemic period, FTT and/or short stature were present in only $25 \%$ of the patients in our study. Lurz et al. (Lurz 2008) reported a frequency of 50\% in Switzerland during 2001-2006. A Finnish study reported that in the 2000 s only $11 \%$ of the CD children were suffering from growth retardation (Savilahti 2010). Moreover, a Dutch study revealed that children in the Netherlands tended to suffer less often from growth failure during recent years 
The four age groups presented in the study differed significantly regardless of the type of presenting symptoms. More specifically, gastrointestinal symtoms and FTT with or without short stature were most common as presenting symptom for the youngest group, i.e. 0-1.9 years. The extra-intestinal symptoms were more common among the oldest children while the screening detected children mostly were between 5 and 14.9 years.

Furthermore, asymptomatic patients were diagnosed significantly more often in the postepidemic period than in the pre-epidemic $(\mathrm{p}=0.001)$ and epidemic $(\mathrm{p}<0.001)$ periods. This could be attributed to the gradual introduction and use in the daily clinical praxis of CD antibodies. During the post-epidemic period the asymptomatic patients represented $13 \%$ of all the new CD cases, twice as many as those reported by Cillerruelo et al. in Spain (Cillerruelo 2014). Different availability of serological screening between countries, as well as difference in the general knowledge of the disease could theoretically lead to a more or less active search for the disease explaining the above results.

The share of the screening detected patients in our study (19\%) during 1997-2013, showed a clear increase when comparing to the other two study periods, and concurring with other studies (Reily 2011, Reily 2012, White 2013). In some cases, regarded initially as asymptomatic, symptoms may be recognised in retrospect after the treatment initiation (Rosén 2011), explaining the arithmetic discrepancy between the asymptomatic patients and the screening cases detected in our study.

The post-epidemic period revealed another significant result, i.e. a decrease in patients with severe symptomatology compared with the pre-epidemic $(\mathrm{p}<0.001)$ and epidemic $(\mathrm{p}<0.001)$ periods. This might reflect an earlier diagnosis due to increased awareness of CD among physicians during the last years. A possible limitation when reporting severity of symptoms, might be the fact that parents tend to exaggerate when describing the health status of the off- 
springs while adolescents can underestimate or even hide their symptoms (Byström 2012, Weimer 2013).

However, the increased knowledge of the disease and the parallel use of the CD serological markers, do not entirely explain the shift observed in the clinical presentation of CD in recent years. For example there was a decrease in diarrheal manifestations, both in adult and pediatric studies, preceding the use of these CD serological markers (Rampertab 2006, Garampazzi 2007). Among the patients of the study cohort, 222 out of $1030(21.6 \%)$ were monosymptomatic. They represented 18\% (18/98) before the celiac epidemic, 13\% (44/319) during and $26 \%$ after (160/613), with a significant increase between the post-epidemic and epidemic period $(\mathrm{p}<0.001)$

\section{Histopathology}

Employing our revised scoring system, biopsy score 3, corresponding to severe enteropathy, was given to $98 \%(95 / 97)$ of the pathology reports from the pre-epidemic, $100 \%(319 / 319)$ from the epidemic, and $93.8 \%$ (534/569) from the post-epidemic period. Patients with severe enteropathy increased significantly during the celiac epidemic compared with the preepidemic period $(\mathrm{p}=0.02)$, but decreased in the post-epidemic period $(\mathrm{p}<0.001)$ compared with the epidemic period.

There is no consensus regarding the possible correlation between the type of mucosal damage and the mode/severity of $\mathrm{CD}$ although numerous studies have employed different clinical, serological, and pathological parameters to assess severity (Weizman 1997, Tursi 2002, Murray 2007, Brar 2007, Thomas 2009, Taavela 2013, Abu Daya 2013). Taking into consideration the significant decrease at the post-epidemic period of the patients with severe enteropathy and the simultaneous increase of the asymptomatic cases during the same period, we have chosen to in- 
terpret these results with great care as a possible indicator of a less severe form of the disease in the recent years.

\section{PAPER II}

\section{Age and sex distribution}

The mean age at diagnosis for the CD population was 6 years (5.7-6.3) while it was 4.9 years (4.7-5.1) for the non-CD patients.

The female-to-male ratio was $1.76: 1$ in the $\mathrm{CD}$ group and $0.93: 1$ in the non-CD group.

\section{Incidence rate}

The highest incidence rate of CD in the present study with 301 new cases per 100,000 person years was reported during the epidemic period for the youngest age group, i.e. 0-1.9 years.

Before this, the incidence rate was gradually increasing. After its peak value in 1994, it started to decrease and reached the lowest value in 2009 with only 10 new cases per 100,000 person years (Figure 6). This decrease has been attributed to the change of feeding recommendations in Sweden after the epidemic period, regarding, e.g. the time of gluten introduction and the amount of gluten intake (Myléus 2009).

The group consisting of older children between 2 and 4.9 years, showed a gradual increase of the incidence rate from the start of the epidemic period continuing even after the end of it. The highest value was recorded in 2013 with 85 new cases per 100,000 person years, though clearly different from the high rates of the youngest group during the epidemic period. At the post-epidemic period both groups moved in parallel (Figure 6).

The patient group aged 5-14.9 years was also defined by a steady increase of the incidence rate, though noticed later compared to the previous group. In 2012 a peak value for this group was noted with 78 new cases per 100,000 person years (Figure 6). 
The incidence rate for the adolescence group (15-17.9 years), started to increase in the epidemic period, but interestingly a total absence of new cases was recorded during some years of that period. The maximum total of new cases per 100,000 person years was 54 in 2010 (Figure 6).

Regarding the total CD population the incidence rate increased gradually during the first years of the epidemic period but decreased temporarily at the end of the period and increased again after 1997, reaching its highest value so far in 2012 with 63 new cases per 100,000 person years (Figure 6).

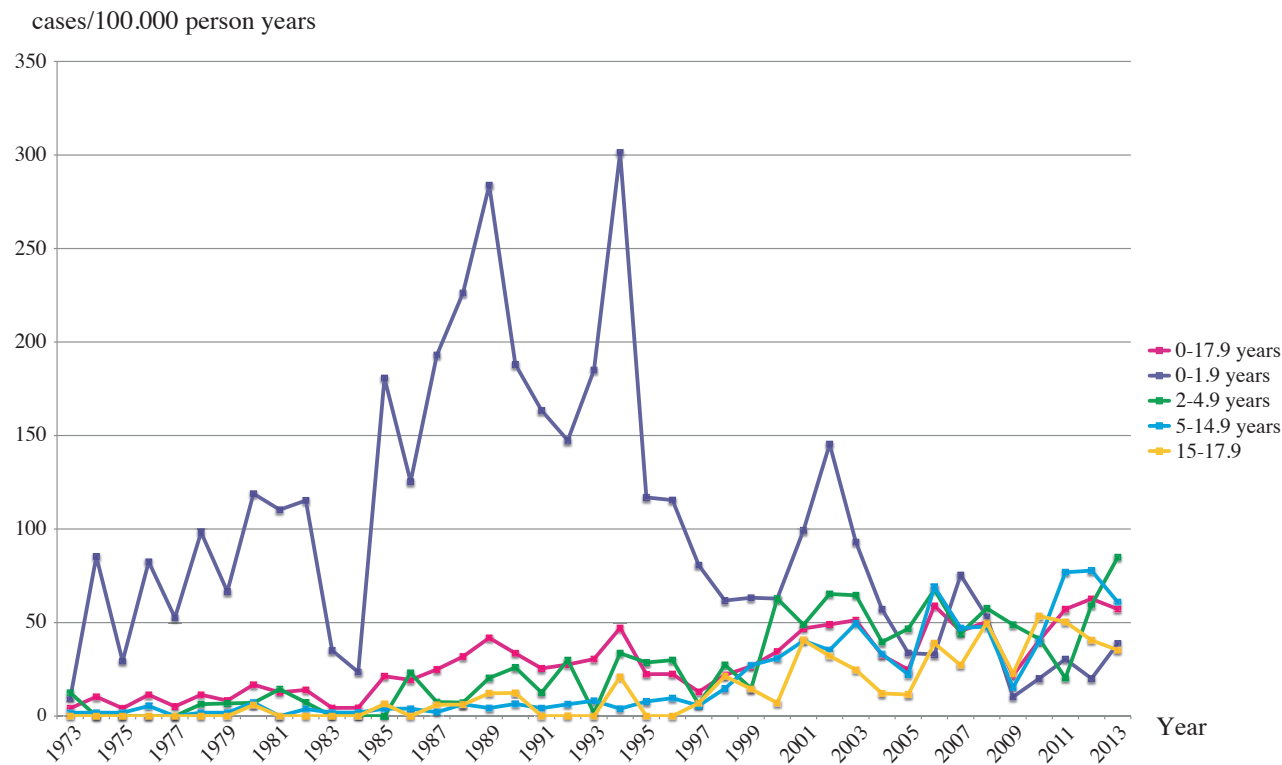

Figure 6. Annual incidence rate of CD in different age groups from 1973 to 2013

Studies from various countries (Ludvigsson 2012, Whyte LA. 2013, White 2013, Namatovu 2014, Zingone F. 2015) confirm the increase of CD incidence rate during the recent years. However, none of them reported as high levels as we did, especially concerning the peak value for the youngest and the whole group with 301 and 63 new cases per 100,000 person years respec- 
tively. The results regarding the incidence rates of the other age groups coincide with the national Swedish rates that Namatovu et al. reported in 2014 (Namatovu 2014).

\section{Cumulative incidence}

The cumulative incidence of the pre-epidemic birth cohort showed a clear tendency of increase until the $12^{\text {th }}$ year of age and remained stable afterwards. For this cohort the highest result reported was 2.7 new cases/1000 births at 12 years of age (Figure 7). Especially for this cohort, our results are consistent with what Namatovu et al. (Namatovu 2014) and Olsson et al. (Olsson 2008) previously reported from Sweden.

The epidemic birth cohort, i.e. including children born between 1984 and 1996, showed an increase up to 2 years, then a fairly stable level until 8 years, followed by a sharp increase of cases with no plateau up to 18 years. The highest value of the cumulative incidence for this group was at 18 years of age with 13.8 new cases/1000 births (Figure 7). Until today the highest cumulative incidence in Sweden was 7 cases/1000 births applying for the epidemic cohort group with follow-up to 14 years of age described by Namatovu et al. (Namatovu 2014). The result from the present study is presumably the highest cumulative incidence rate reported globally (Corrao 1996, Cook 2004, Cilleruelo 2014).

Up to 9 years of age the youngest cohort displayed a moderate increase but after that the cumulative incidence was stabilised. The highest cumulative incidence for this particular cohort was reported at 15 years of age with 7.1 new cases/1000 births (Figure 7). The results for the post-epidemic period corroborate those from the national register of Spain indicating cumulative incidence of 7 new cases/1000 births (Cilleruelo 2014). 


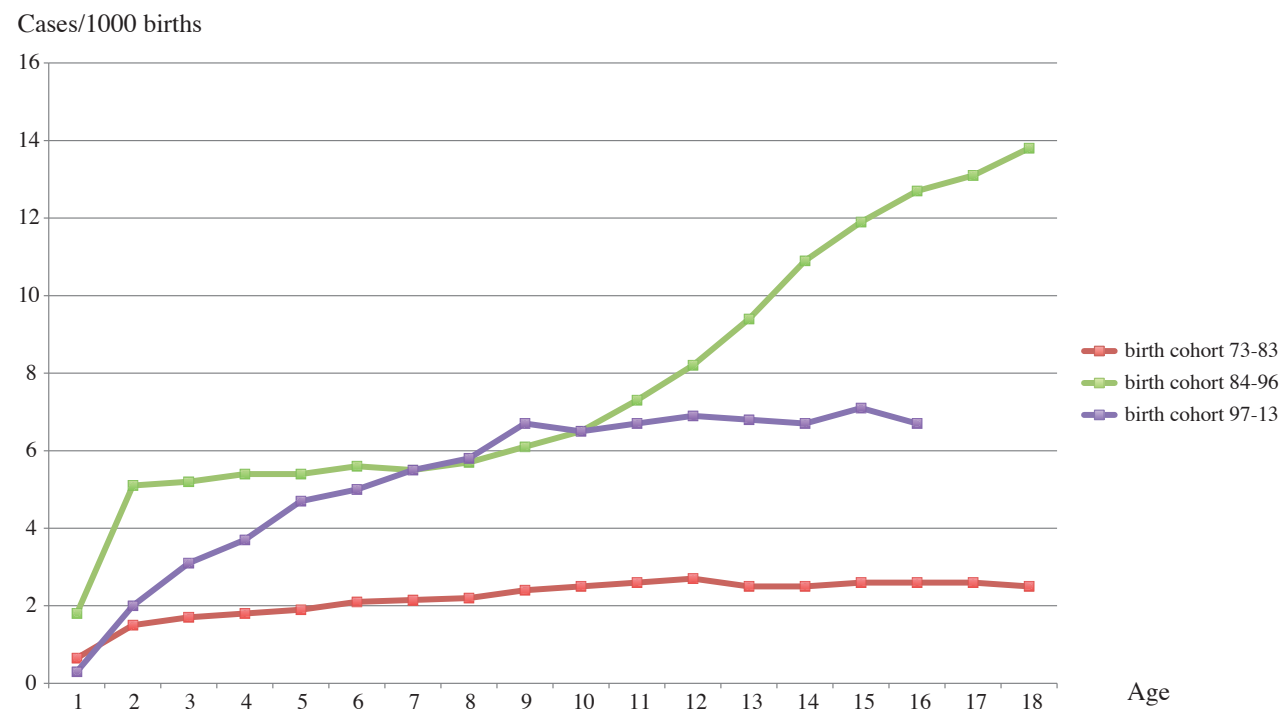

Figure 7. Cumulative incidence of CD by age for the birth cohorts 1973-1983 (pre-epidemic period), 1984-1996 (epidemic period), and 1997-2013 (post-epidemic period)

\section{Diagnostic activity}

The mean value of the diagnostic activity, i.e. the proneness to perform SBB, during the preepidemic period was 0.45 , followed by an increase to 1.07 in the epidemic period and a subsequent decline to 0.69 in the post-epidemic period. The difference between the three periods was significant $(\mathrm{p}<0.001)$. The diagnostic activity as shown in Figure 8 reached a peak value of 1.55 in 1990 .

During the 1970s when SBB became the diagnostic tool for diagnosing CD in the county, diagnostic activity increased drastically (Figure 8). Patients who were investigated with SBB at that time were those with prominent symptoms. At the end of the pre-epidemic period diagnostic activity decreased (Figure 8). A new increase occurred in the mid 1980s coinciding with: the introduction of AGA, known for their high sensitivity (Volta 2011); the high number of infants presenting with typical clinical symptoms during the epidemic period; and an in- 
crease of the incidence rate. All these changes could have affected the diagnostic activity. At the end of the epidemic period, the diagnostic activity decreased in parallel with the incidence rate. In the end of $1990 \mathrm{~s}$, when the majority of the CD subjects were investigated with EMA, which have proved to be very specific (Volta 2011), the diagnostic activity increased again as well as the incidence rate of CD did. Since 1994 and onwards, both the diagnostic activity and the incidence rate demonstrated parallel changes (Figure 8).

The parallel changes of diagnostic activity, shifts of the incidence rate of $\mathrm{CD}$, and introduction and use of various antibodies during the past years hampers our ability to draw conclusions about the proneness to perform SBB.

\section{Diagnostic accuracy}

The mean value of diagnostic accuracy for the pre-epidemic, epidemic, and post-epidemic periods was $0.38,0.24$ and 0.56 , respectively (Figure 8) with a significant difference between the three study periods $(\mathrm{p}<0.001)$. The diagnostic accuracy increased gradually reaching in 2012 a peak value of 0.87 (Figure 8 ).

Since 1984 the diagnostic accuracy has increased steadily reaching the top value of 0.87 in 2012. Notably, this is very close to the value observed in 1973. From the mid 1980s changes in diagnostic activity are in line with the shifts of the incidence rate. However, it is difficult to explain the decrease of diagnostic accuracy from 1973 until 1983. 


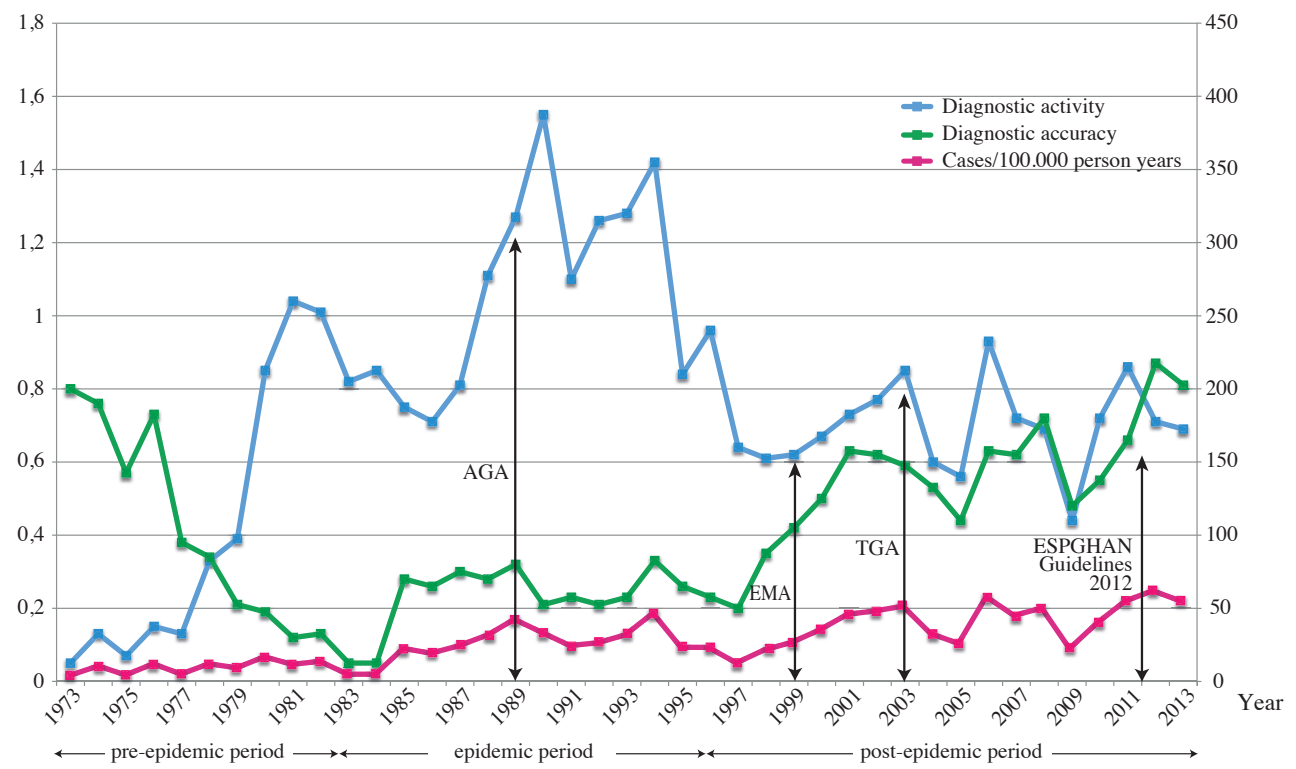

Figure 8. Diagnostic activity and accuracy among Swedish children investigated for CD with biopsy between 1973 and 2013. Arrows indicate when AGA, EMA, t-TGA were used in $>50 \%$ of the cases investigated for CD but also the introduction of the 2012 ESPGHAN guidelines for $\mathrm{CD}$ diagnosis in the clinical praxis. Diagnostic activity was considered as the number of subjects biopsied per 1,000 children in the study population. Diagnostic accuracy was specified as the number of CD cases per total number of children with suspected CD who underwent biopsy. The purple line represents the incidence rate of $\mathrm{CD}$ in the pediatric population during the same time period

\section{Histopathological evaluations}

In the CD group, $2.9 \%$ (29/987) of the patients had a biopsy result revealing a mild enteropathy, i.e. Alexander II, Marsh 1 and 2, and/or KVAST borderline. In the CD group the frequency of patients with mild enteropathy was significantly different between the pre-epidemic $(n=2,2 \%)$, epidemic $(n=1,0.03 \%)$, and post-epidemic period $(n=26,4.5 \%)(p=0.003)$.

The biopsies of patients allocated to the non-CD group, revealed mild enteropathy in $8.2 \%$ $(142 / 1732)$ of the cases. The frequency of patients with mild enteropathy was also significantly different between the pre-epidemic $(n=113,31.3 \%)$, epidemic $(n=14,1.5 \%)$, and postepidemic period $(\mathrm{n}=16,3.6 \%)(\mathrm{p}<0.001)$. 
Regarding the whole study population, a significant decrease of the cases with mild enteropathy was found between the pre-epidemic period and both the epidemic $(\mathrm{p}<0.001)$ and postepidemic periods $(\mathrm{p}<0.001)$. Cases of mild enteropathy were more frequent in the group of non-CD patients $(8.2 \%)$ compared to the CD group $(2.9 \%)(\mathrm{p}<0.001)$.

A total of 41 among the 142 cases of mild enteropathy from the non-CD group, underwent a second SBB because of inconclusive findings and remaining high CD suspicion. All these subjects continued being regarded as non-CD patients after the second biopsy with 23/41 showing a less pathologic histological picture while 18/41 unchanged. None of the 101 remaining cases underwent a renewed biopsy before their $18^{\text {th }}$ year of age.

In our study the cases of mild enteropathy accounted for $6.3 \%(172 / 2719)$ of the whole study population, which is three times higher than in an adult group of 66 patients reported by Mahadeva et al. (Mahadeva 2002) and five times higher than in a retrospective study from the Mayo Clinic (Kakar 2003).

Our material consisted of pathology reports done by several pathologists during the 41-year study period. It has been reported that the agreement between different pathologists concerning Marsh score 1 and 2 was poor (Arguelles-Grande 2012), a fact that could be considered a bias source in the present study. On the other hand, the Marsh score at the ends of the diagnostic spectrum, i.e. Marsh 0 and Marsh 3c, had an optimal agreement (Arguelles-Grande 2012). A Swedish-Danish study of interobserver variation in diagnosing pediatric CD revealed moderate agreement among different pathologists (Weile 2000). Mubarak et al. reported discrepancy with underdiagnosis of pediatric CD between two independent evaluations in $7.4 \%$ of the cases (Mubarak 2011). All these facts make clear that the reevaluation of our whole material by one pathologist would have been optimal, but unfortunately was not feasible in this study. 


\section{PAPER III}

The mean age of the study population was $12 \pm 0.2$ years and the male-to-female ratio 1:1.7.

\section{GFD compliance}

The mean duration of GFD consumption in the study group was $6.9 \pm 0.3$ years.

The majority (96.8\%), of our study population claimed strict compliance with the diet.

In other questionnaire-based reports the percentage of $\mathrm{CD}$ children who are compliant with a GFD varied from 30\% to 95\% (Jackson 1985, Kumar 1988, Mayer 1991, Ljungman 1993, Mariani 1998 Tommassini 2004, Rashid 2005).

Studies with a multimethod investigation of the diet compliance, i.e. questionnaires along with antibody testing, revealed discrepancies between $6 \%$ and $28.5 \%$ and the diet adherence was higher when using self-reporting compared to serological determination (Mariani 1998, Tommasini 2004, Hommel 2008, Jardesin 2008, Webb 2015). The fact that antibody analyses were not performed consistently in our study population could be considered a flaw. The risk of recall bias associated with a retrospective questionnaire study could possibly explain possible overestimation of adherence when assessed without serological testing. People are more likely to remember mistakes that have happened more recently (Hommel 2008).

The study included children who came for their yearly check-up at our outpatient department. Probably patients who abstained from the follow-up visit might have been less strict in their diet, resulting in selection bias and influencing adherence results.

Gender, current age, and consumption of oats in the GFD, did not influence adherence to the diet (Table 6). On the contrary, the duration of the GFD consumption affected the adherence significantly suggesting that children consuming the diet for more than 15 years were less adherent (Table 6). Our results are not in agreement with Kurppa et al. (Kurppa 2012) who suggested that the age at CD diagnosis and the current age of the patient could influence the GFD compliance. 
Table 6. Gender, age, duration of gluten-free diet (GFD), and oats consumption in relation to adherence to a GFD in children with celiac disease $(n=316)$

\begin{tabular}{lccc}
\hline & Subjects & Adherence (\%) & p-value* \\
\hline Gender & & & 0.282 \\
Female & 206 & 94 & \\
Male & 114 & 98 & \\
Age (years) & & & 0.296 \\
$0-5$ & 18 & 100 & \\
$5.1-10$ & 119 & 98 & \\
$10.1-18.5$ & 178 & 96 & \\
Duration of GFD (years) & & & 0.001 \\
$0-5$ & 130 & 98 & \\
$5.1-10$ & 92 & 98 & \\
$10.1-15$ & 72 & 99 & \\
$>15$ & 22 & 82 & \\
Oats consumption & & & \\
Yes & 282 & 97 & \\
No & 34 & 97 & \\
\hline
\end{tabular}

* Differences in frequencies were tested with the chi-square test/Fischer's exact test

Accidental gluten transgressions were reported by $263(83.2 \%)$ of the children. The vast majority of the cases regarded mistakes that took place once or twice while on a GFD. On the contrary $14.9 \%$ reported no diet-related mistakes, and $1.9 \%$ could not tell whether such mistakes had occurred.

Accidental gluten consumption took place under different conditions (Table 7), results also shown by others however in different proportions (Ljungman 1993, Mc Culloch 2014). 
Table 7. Percentage of the children $(n=162)$ who accidentally consumed gluten during different occasions

\begin{tabular}{lc}
\hline Places of accidental gluten intake & Percentage \\
\hline Childcare & 33.2 \\
Home & 20.5 \\
Visitng friends and relatives & 16.4 \\
Do not remember & 13.8 \\
Playgrounds/training places & 6.7 \\
Restaurants & 6.4 \\
Journeys & 3.0 \\
\hline
\end{tabular}

The intake of gluten-containing foods by mistake included a variety of products presented in Table 8 .

Table 8. Percentage of the children $(n=162)$ who accidentally consumed different types of food containing gluten

\begin{tabular}{lc}
\hline $\begin{array}{l}\text { Type of food with gluten accidentally } \\
\text { consumed }\end{array}$ & Percentage \\
\hline Bakery products & 23.6 \\
Pancakes, pizzas, beverages, soy etc. & 17.2 \\
Bread & 13.5 \\
Snacks & 11.3 \\
Do not remember & 11 \\
Pasta & 8.9 \\
Sauce & 6.1 \\
Cereals & 4.6 \\
Do not know & 3.7 \\
\hline
\end{tabular}

Thirty-eight percent of the children consumed by mistake only small portions of gluten $(<4$ $\mathrm{g}), 17.1 \%$ ingested medium portions of gluten ( $4-9 \mathrm{~g})$ and $24 \%$ had large amounts ( $>9 \mathrm{~g})$. In $20.9 \%$ of the cases, they could not recall the quantity they had consumed.

A total of $162 / 263$ children $(61.6 \%)$ experienced symptoms after an incidental intake of gluten and $87.5 \%$ of them had symptoms from the gastrointestinal tract. A variety of symptoms was experienced and is shown in Table 9. These results differ from previous reports which indicated that many of the patients $(>50 \%)$ did not experience symptoms at all 
after gluten intake, especially of small amounts (Kumar 1988, Mayer 1991). A Canadian study reported reactions in $54 \%$ of the cases with and a similar pattern of experienced symptoms, but in different proportions (Rashid 2005).

Table 9. Number of children with celiac disease showing different symptoms after incidental intake of gluten

\begin{tabular}{lcc}
\hline Symptom & Number* & Percentage** $^{*}$ \\
\hline Abdominal pain & 105 & 64.8 \\
Vomiting & 54 & 33.3 \\
Diarrhea & 39 & 24.1 \\
Tiredness & 11 & 6.8 \\
Nausea & 10 & 6.2 \\
Gases & 5 & 3.1 \\
Constipation & 4 & 2.5 \\
Headache & 4 & 2.5 \\
Other & 13 & 8.0 \\
Do not remember & 3 & 1.8 \\
\hline
\end{tabular}

*Number of individuals with that particular symptom, i.e. each child could experience more than one symptom.

**Percentage of the children $(\mathrm{n}=162)$ who experienced symptoms.

The timepoint that the patients experienced symptoms after the gluten consumption differed (Table 10). Rashid et al. reported median reaction time ranging from 25 minutes to 60 hours (median: 2 hours) (Rashid 2005).

Table 10. Number of children with celiac disease showing symptoms in different time intervals after accidental gluten intake

\begin{tabular}{lcc}
\hline Time interval & Number & Percentage* \\
\hline $0-1 \mathrm{~h}$ & 57 & 35.2 \\
$1-3 \mathrm{~h}$ & 53 & 32.7 \\
$3-6 \mathrm{~h}$ & 8 & 4.9 \\
$6-12 \mathrm{~h}$ & 6 & 3.7 \\
$12-24 \mathrm{~h}$ & 4 & 2.5 \\
$>24 \mathrm{~h}$ & 12 & 7.4 \\
Do not remember & 22 & 13.6 \\
\hline
\end{tabular}

*Percentage of the children $(\mathrm{n}=162)$ who experienced symptoms 
There was no strong correlation between the amount of accidental gluten intake and the time of the début of the symptoms $(\rho=0.01)$. Laurin et al. reported that symptoms after a gluten challenge, with a variety of gluten amounts occurred after a median of 8 days (Laurin 2002). However, the patients were fed with gluten on a daily basis, in comparison with our patients who consumed gluten mainly in small amounts and by accident.

The majority (62\%) of the patients did not experience any problems when trying to comply with the GFD, but more than $36 \%(115 / 316)$ did, and $1.6 \%$ did not answer the question. Ljungman et al. showed that even a larger proportion of patients $(77.0 \%)$, did not experience the GFD as troublesome in their study (Ljungman 1993).

\section{Oats and GFD}

A total of 282 patients $(89.2 \%)$ in our study population were including oats in their GFD. Among them, $81.9 \%$ ate pure oats, $13.1 \%$ ordinary oats, and the rest could/did not answer the question. The mean period of oats consumption in the GFD was $3.4 \pm 0.1$ years. Oats consumption was not related to the age of the patients $(\mathrm{p}=0.68)$. The first oats-containing food our study subjects tried were in descending order: homemade chocolate balls, porridge, muesli, bread, and cakes. The frequency of oats consumption in the study group is shown in Table 11.

Table 11. Frequency and number of children with celiac disease consuming oats

\begin{tabular}{lcc}
\hline Frequency & Number & Percentage* $^{*}$ \\
\hline$<1$ time/week & 128 & 45.3 \\
$1-3$ times/week & 63 & 22.4 \\
$4-6$ times/week & 39 & 13.8 \\
1 time/day & 24 & 8.5 \\
$>1$ time/day & 18 & 6.4 \\
No answer & 10 & 3.6 \\
\hline
\end{tabular}

*Percentage of the children $(\mathrm{n}=282)$ in the study who consumed oats 
Among the study subjects who excluded oats from their diet $(10.8 \%, n=34), 13$ had previously eaten oats, 12 had never tried, and 9 did not answer the question. Those who abstained from oats after having tried them, either did not like the taste $(n=8)$ or experienced symptoms $(n=2)$, e.g. abdominal pain and loose stools. Two children gave no specific reason and one did not answer this question. Another third $(n=12)$ had not tried oats at all. This could indicate fear of symptoms, alternately, lack of information about the safety of oats and their possible beneficial effects (Størsrud 2003 a, Størsrud 2003 b, Richman 2011, Clemens 2014).

\section{PAPER IV}

The mean age of the study group was 12 years and the male-to-female distribution was 1:1.5. Among the 188 children of the study group, $96.2 \%$ reported that they had been consuming a strict GFD. The mean period of GFD consumption was 7.1 years. A total of $168(89.4 \%)$ children included oats in the diet and $99.4 \%$ of them ate purified oats. The mean period of oats consumption was 3.6 years (median 3, range 2-6 years).

Food products potentially rich in nitrite/nitrate had been ingested by 79 (42\%) within the 24 hours preceding the urine sampling, e.g. beetroots by 36 patients, sausages by 22 , bacon/turkey by 13 , and spinach by five. In 17 patients asthma was previously diagnosed and two study subjects were treated with antibiotics due to an on-going urinary tract infection at the timepoint of urine sampling.

\section{Nitric oxide measurements}

Measurements of urinary NO metabolites in the study population revealed a median concentration of $980 \mu \mathrm{M}$ (range $0-4029 \mu \mathrm{M}$ ), regardless if the patients were consuming oats or not in their GFD. Sundqvist et al. in the first study of urinary NO metabolites in CD included refer- 
ence children, i.e. patients with gastrointestinal symptoms who underwent a SBB on CD suspicion but were considered not having CD. They had a mean nitrite/nitrate concentration of $1174 \pm 116 \mu \mathrm{M}$. In the present study, we have used as cut-off their mean value +2 SEM, i.e. $1400 \mu \mathrm{M}$ (Sundqvist 1998). After applying this cut-off value, our study population was decomposed into two distinct subpopulations (population $\mathrm{nr} 1:<1400 \mu \mathrm{M}$; population $\mathrm{nr} 2$ : $>1400$ $\mu \mathrm{M})$ (Figure 9). The first population comprised 134 (71.3\%) and the second 54 subjects (28.7\%). The median concentration of urinary NO metabolites for the first subpopulation was $804 \mu \mathrm{M}$ (range $0-1315 \mu \mathrm{M}$ ) and for the second $1956 \mu \mathrm{M}$ (range 1424-4029 $\mu \mathrm{M}$ ).

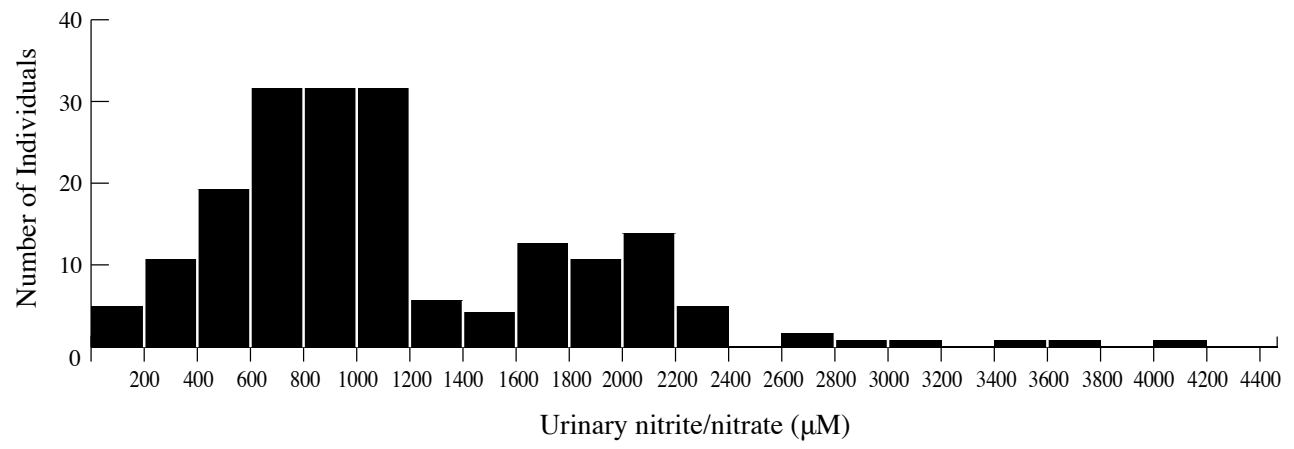

Figure 9. The number of children with coeliac disease on gluten-free diet with specific urinary NO metabolite concentrations. The figure shows two different subpopulations with median concentration for the first population at $803.5 \mu \mathrm{M}$ or the first population and $1956 \mu \mathrm{M}$ for the second

Those two subpopulations did not differ statistically regarding age, sex, strictness of GFD, duration of GFD, oats consumption in the GFD, or purity of oats (Table 12). 
Table 12. Compliance to GFD, oats consumption, sex, and age in children with coeliac disease $(n=188)$, in the subgroups with normal and high concentrations of urinary NO metabolites, respectively

\begin{tabular}{lccc}
\hline & $\begin{array}{c}\text { Subjects with } \\
<\mathbf{1 4 0 0} \boldsymbol{\mu} \mathbf{M} *\end{array}$ & $\begin{array}{c}\text { Subjects with } \\
>\mathbf{1 4 0 0} \boldsymbol{\mu M} *\end{array}$ & p-value \\
\hline Strictness of GFD & 128 & 53 & 0.389 \\
Yes & 6 & 1 & \\
No & & & 0.923 \\
Duration of GFD & & & \\
(years) & 31 & 13 & \\
$0-3$ & 54 & 24 & \\
$3.1-8$ & 27 & 9 & 0.361 \\
$8.1-13$ & 22 & 8 & \\
$>13.1$ & 118 & 50 & 0.620 \\
Oats Consumption & 16 & 4 & \\
Yes & & & \\
No & 120 & 47 & 0.515 \\
Purity of oats & 14 & 7 & \\
Yes & & & \\
No & 35 & 19 & 0.389 \\
Sex & 80 & 54 & \\
Male & & & \\
Female & 5 & 22 & \\
Age (years) & 55 & 29 & \\
$0-5$ & 74 & & \\
$5.1-12$ & & & \\
$12.1-18.18$ & 5 & & \\
\hline
\end{tabular}

* Urinary concentration of the nitric oxide metabolites nitrite and nitrate

Moreover, no correlation was found between the duration of oats consumption and concentration of urinary NO metabolites $(\rho=0.102$ and $p$-value $=0.201)$.

The outcome was influenced neither by the intake of nitrite/nitrate rich food 24 hours before the urine sampling, on-going urinary tract infection during the sampling, nor an asthma diagnosis (Table 13).

There was no significant difference between the results in children who had eaten food rich in nitrite/nitrate prior to urine sampling compared to non-eaters (Table 13). 
Table 13. Listing of factors that could possibly affect the levels of NO metabolites in the urine of children with coeliac disease $(n=188)$

\begin{tabular}{|c|c|c|c|}
\hline & $\begin{array}{l}\text { Subjects with } \\
<1400 \mu \mathrm{M} *\end{array}$ & $\begin{array}{l}\text { Subjects with } \\
>1400 \mu \mathrm{M} *\end{array}$ & p-value \\
\hline Asthma & & & 0.554 \\
\hline Yes & 13 & 4 & \\
\hline No & 119 & 52 & \\
\hline $\begin{array}{l}\text { Urinary tract infec- } \\
\text { tion }\end{array}$ & & & 0.498 \\
\hline Yes & 1 & 1 & \\
\hline No & 132 & 52 & \\
\hline Smoked ham & & & 0.654 \\
\hline Yes & 25 & 11 & \\
\hline No & 109 & 40 & \\
\hline Sausage/salami & & & 0.419 \\
\hline Yes & 14 & 8 & \\
\hline No & 118 & 46 & \\
\hline Other smoked food & & & 0.396 \\
\hline Yes & 8 & 5 & \\
\hline No & 124 & 57 & \\
\hline Spinach & & & 0.156 \\
\hline Yes & 5 & 0 & \\
\hline No & 128 & 52 & \\
\hline Beetroots & & & 0.844 \\
\hline Yes & 2 & 1 & \\
\hline No & 130 & 51 & \\
\hline
\end{tabular}

* Urinary concentration of the nitric oxide metabolites nitrite and nitrate

Studies have shown that dietary NO did not have significant influence in the fasting morning NO concentrations of healthy individuals (Grabowski 1996). In our study, consumption of nitritre/nitrate rich food by some subjects 24 hours before the urine sampling, followed by a fasting period, did not affect the NO metabolite concentrations.

Regardless of the oats consumption in the GFD there was no significant difference concerning the urinary NO concentrations. The majority, $71 \%$, of the patients who had consumed oats in their GFD more than one year had a low excretion of urinary nitrite/nitrate. Some, (29\%), still demonstrated high levels raising the question whether there was an on-going mucosal in- 
flammation not necessarily accompanied with mucosal alterations. There was no indication that these patients had eaten gluten by mistake, as they reported high diet adherence. Hollén et al. described reductions in urinary nitrate/nitrite products in $\mathrm{CD}$ children consuming oats for one year, but there were still high levels of NO metabolites in the urine of almost one third of them although their SBB was normal, suggesting a need for long-term follow up of the patients (Hollén 2006). Sjöberg et al. showed that highly cytotoxic IELs persist in a considerable fraction of CD patients consuming oats for one-year period (Sjöberg 2014). Another study reports increased fecal concentrations of short chain fatty acids, especially of acetic acid, which can promote an inflammatory process, in patients consuming oats in their GFD for one year in comparison to children on a traditional GFD. Those results can be indicative for an on-going inflammation among some children consuming oats (Tjellström 2014). 


\section{CONCLUSIONS}

The mean age a diagnosis of pediatric CD in Sweden increased over the last 15 years. Currently, $\mathrm{CD}$ shows a milder picture in terms of less severe clinical symptomatology, fewer cases of severe enteropathy according to pathology reports, more patients with monosymptomatic disease, i.e. a less complicated clinical picture, and more asymptomatic subjects detected through screening. The frequency of patients with gastrointestinal, extra-intestinal symptoms and FTT and/or short stature as a presenting symptom of CD decreased over the years. The gastrointestinal symptoms were the most common presenting symptom in all age groups studied and during the whole study period. The extra-intestinal symptoms were more common among older children, whereas the gastrointestinal symptoms and FTT and/or short stature were present mainly in the younger group. The change in clinical picture should be acknowledged in the care of children and adolescents with possible celiac disease.

The incidence rate of Swedish CD children continued to increase even after "Swedish celiac epidemic" period. Our data on the cumulative incidence at 18 years of age for the epidemic birth cohort reached, to our knowledge, the highest number up to date reported in the literature. The diagnostic activity and accuracy when performing SBB for the CD investigation has increased significantly through the years. The increase could not clearly be attributed to the use of antibody screening in clinical praxis due to other parallel changes in feeding recommendations, diagnostic aptitude and general knowledge of the disease. The cases of mild enteropathy were mostly considered as non-CD patients and their frequency decreased over the years. 
The general compliance to the GFD was high. Only the long duration of the GFD appeared to influence the diet adherence negatively. However, accidental transgressions occurred for most of the patients, though rarely. In most of the cases, mistakes took place when the patients were not at home. Symptoms after incidental gluten intake were experienced mostly from the gastrointestinal tract. Oats have been accepted and added to the GFD in our study population. The majority consumed purified oats without reporting major complications concerning their well-being.

The urinary levels of NO metabolites in CD patients, who had consumed oats in their GFD more than one year, revealed two subpopulations, one with high and one with low levels. No differences were found between the two populations regarding sex, age, compliance to the GFD. Nitrate-rich foods, asthma or urinary tract infection did not affect the result. The high levels could be caused by poor adherence to the GFD, sensitivity to oats, or some unknown factor(s). The elevated levels of NO metabolites could indicate mucosal inflammation and pinpoint the need of careful follow-up of children including oats in their GFD. 


\section{ACKNOWLEDGMENTS}

I wish to express my sincere gratitude and appreciation to all children and their parents, who have participated in all four studies of the present thesis.

Many have contributed during the years, in different ways, to the completion of this work.

I specially would like to thank:

- Karin Fälth-Magnusson, my supervisor, for guiding me during my whole journey through the research world. Thank you for never ending generosity and enthusiasm, for your patience and incomparable flexibility. I am grateful for your skilled, energetic and pedagogical tutoring.

- Elisabet Hollén, co-supervisor, for her never failing positive energy, constructive support and valuable comments. Thank you for your empathic ability and for being always available.

- Lars Stenhammar, co-author (study III-IV) for introducing me to the CD world and gladly sharing his undeniable knowledge both as a clinician and researcher.

- Karl-Eric Magnusson for his valuable comments, especially the linguistic ones through my $\mathrm{PhD}$ journey.

- Tommy Sundqvist, co-author (study IV) for expert guidance especially in the field of statistics.

- Tony Forslund, co-author (study IV) for NO analysis.

- Lotta Högberg, co-author (study III-IV) for providing data concerning patients from Norrköping.

- Jan-Åke Hammersjö, co-author (study III) for data concerning patients from Västervik.

- Ann-Louise Karlsson for excellent help in finding the original files. 
- Nina Nelson, for encouraging me to enter the world of research and establishing the first contact between me and my supervisor Karin Fälth-Magnusson.

- Lena Grahnqvist, my former chief for giving the opportunity to continue seamlessly my research and believing in me.

- Henrik Arnell, my current chief for providing me time to complete my thesis.

- Maurice Devenney for lingusitic advice in papers I,II,III.

- Peter Cox for lingustic advice in paper IV.

- Karl Wahlin for excellent help with the statistical part.

- Lennart Franzén for valuable advice on the quality assessments of histopathologic evaluations.

- All my colleages and co-workers at the Astrid Lindgrens Children Hospital, especially those working at the Department for Pediatric Gastroenterology, Hepatology and Nutrition.

- The University of Linköping for accepting me as a PhD student.

- Forum GIMIICum (Research School of Gastrointestinal Inflammation and Infection) for useful meetings enriching my knowledge on the gastointestinal function.

- The helpful staff at the pediatric units in Linköping, Norrköping and Motala for taking care of the patients and collecting clinical data.

- Hospital archive personnel in Linköping and Motala for their help in documenting data.

- My mother, my sister, my brother in-law, my nephew and my grandmother for all their love and constant support and for making me a better person.

- In loving memory of my father and grandfather.

- All the other members of my family. 
- All my friends, especially Eleni Mentesidou, Ioannis Kollias and Maria Paschou for being there for me the last 16 years, for listening to my grumblings but still loving me.

- My best friend Spyros Taramigkos for creating the cover of the thesis and helping me with his undeniable graphic design skills in all four papers. 


\section{REFERENCES}

Akobeng AK, Thomas AG. Systematic review: tolerable amount of gluten for people with coeliac disease. Aliment Pharmacol Ther. 2008 Jun 1;27(11):1044-52.

Alaedini A, Green PH. Narrative review: celiac disease: understanding a complex autoimmune disorder. Ann Intern Med. 2005 Feb 15;142(4):289-98.

Alexander JO. Dermatitis herpetiformis. Major problems in dermatology. A. Rock. London, Saunders Co Ltd. 1975: 236-80.

Anania C, De Luca E, De Castro G, et al. Liver involvement in pediatric celiac disease. World J Gastroenterol. 2015 May 21; 21(19): 5813-22.

Aranke M, Bryan NS, Mian AI. Towards nitric oxide based diagnostics: call to action. Trends Mol Med. 2011 Nov; 17(11): 614-6.

Arentz-Hansen H, Fleckenstein B, Molberg Ø, et al. The molecular basis for oat intolerance in patients with celiac disease. PLoS Med. 2004 Oct; 1(1): e1.

Arguelles-Grande C, Tennyson CA, Lewis SK, et al. Variability in small bowel histopathology reporting between different pathology practice settings: impact on the diagnosis of coeliac disease. J Clin Pathol. 2012 Mar; 65(3): 242-7.

Aronsson CA, Lee HS, Liu E, et al; TEDDY STUDY GROUP. Age at gluten introduction and risk of celiac disease. Pediatrics. 2015 Feb; 135(2):239-45.

Ascher H, Holm K, Kristiansson B, et al. Different features of coeliac disease in two neighbouring countries. Arch Dis Child. 1993 Sep; 69(3): 375-80.

Auricchio S, Follo D, de Ritis G, et al. Does breast feeding protect against the development of clinical symptoms of celiac disease in children? J Pediatr Gastroenterol Nutr. 1983; 2(3): 42833.

Bevan S, Popat S, Braegger CP, et al. Contribution of the MHC region to the familial risk of coeliac disease. J Med Genet. 1999 Sep; 36(9): 687-90.

Björck S, Lindehammer SR, Fex M, et al. Serum cytokine pattern in young children with screening detected coeliac disease. Clin Exp Immunol. 2015 Feb; 179(2):230-5.

Bonamico M, Thanasi E, Mariani $\mathrm{P}$, et al. ; Società Italiana di Gastroenterologica, Epatologia, e Nutrizione Pediatrica. Duodenal bulb biopsies in celiac disease: a multicenter study. J Pediatr Gastroenterol Nutr. 2008 Nov; 47(5):618-22.

Bonamico M, Mariani P, Thanasi E, et al. Patchy villous atrophy of the duodenum in childhood celiac disease. J Pediatr Gastroenterol Nutr. 2004 Feb; 38(2):204-7. 
Bories PN, Bories C. Nitrate determination in biological fluids by an enzymatic one-step assay with nitrate reductase. Clin Chem. 1995 Jun; 41(6 Pt 1):904-7.

Branski D. New Insights in Celiac Disease. Rambam Maimonides Med J. 2012 Jan; 3(1): e0006. Published online 2012 Jan 31.

Byström IM, Hollén E, Fälth-Magnusson K, et al. Health-related quality of life in children and adolescents with celiac disease: from the perspectives of children and parents. Gastroenterol Res Pract. 2012; 2012: 986475.

Catassi C, Fabiani E, Iacono G, et al. A prospective, double-blind, placebo-controlled trial to establish a safe gluten threshold for patients with celiac disease. Am J Clin Nutr. 2007 Jan; 85(1):160-6.

Chorzelski TP, Sulej J, Tchorzewska H, et al. IgA class endomysium antibodies in dermatitis herpetiformis and coeliac disease. Ann N Y Acad Sci. 1983;420:325-34.

Ciclitira PJ, Johnson MW, Dewar DH, et al. The pathogenesis of coeliac disease. Mol Aspects Med. 2005 Dec; 26(6):421-58.

Cillerruelo ML, Roman-Riechmann E, Sanchez-Valverde F, et al. Spanish national registry of celiac disease: incidence and clinical presentation. J Pediatr Gastroenterol Nutr. 2014 Oct; 59(4): 522-6.

Ciuk J, Volkmer RE, Edwards JW. Domestic nitrogen oxide exposure, urinary nitrate, and asthma prevalence in preschool children. Arch Environ Health. 2001; 56(5): 433-8.

Clemens R, van Klinken BJ. The future of oats in the food and health continuum. Br J Nutr. 2014 Oct; 112 Suppl 2: S75-9.

Cook B, Oxner R, Chapman B, et al. A thirty-year (1970-1999) study of coeliac disease in the Canterbury region of New Zealand. N Z Med J. 2004 Feb 20; 117(1189): U772.

Corrao G, Usai P, Galatola G, et al. Estimating the incidence of coeliac disease with capturerecapture methods within four geographic areas in Italy. J Epidemiol Community Health. 1996 Jun; 50(3): 299-305.

Csizmadia CG, Mearin ML, von Blomberg BM, et al. An iceberg of childhood coeliac disease in the Netherlands. Lancet. 1999 Mar 6; 353(9155): 813-4.

Daniels I, Cavill D, Murray IA, et al. Elevated expression of iNOS mRNA and protein in coeliac disease. Clin Chim Acta. 2005; 356(1-2): 134-42.

Dicke WK, Weijers HA, van de Kamer JH. Coeliac disease. II. The presence in wheat of a factor having a deleterious effect in cases of coeliac disease. Acta Paediatr Stockh 1953;42:34-42.

Dicke WK. Een onderzoek naar de nadelige invloed van sommige graansoorten op de lijder aan Coeliakie (Dissertation Utrecht 30. Mai 1950). 
Dielli-Crimi R, Cénit MC, Núñez C. The genetics of celiac disease: A comprehensive review of clinical implications. J Autoimmun. 2015 Jul 17. pii: S0896-8411(15)30004-4.

Dieterich W, Esslinger B, Schuppan D. Pathomechanisms in celiac disease. Int Arch Allergy Immunol. 2003 Oct; 132(2): 98-108.

Dieterich W, Ehnis T, Bauer M, et al. Identification of tissue transglutaminase as the autoantigen of celiac disease. Nat Med.1997 Jul; 3(7): 797-801.

Di Sabatino A, Lenti MV, Giuffrida P, et al. New insights into immune mechanisms underlying autoimmune diseases of the gastrointestinal tract. Autoimmun Rev. 2015 Aug 12.

Dubé C, Rostom A, Sy R, et al. The prevalence of celiac disease in average-risk and at-risk Western European populations: a systematic review. Gastroenterology. 2005 Apr; 128(4 Suppl 1): S57-67.

du Pré MF, Sollid LM. T-cell and B-cell immunity in celiac disease. Best Pract Res Clin Gastroenterol. 2015 Jun; 29(3):413-23.

ESPGAN committee on nutrition. Guidelines on infant nutrition. III. Recommendations for infant feeding. Acta Paediatr Scand Suppl. 1982; 302:1-27.

Fabiani E, Taccari LM, Rätsch IM, et al. Compliance with gluten-free diet in adolescents with screening-detected celiac disease: a 5-year follow-up study. J Pediatr. 2000 Jun; 136(6):841-3.

Fasano A (a). Clinical presentation of celiac disease in the pediatric population. Gastroenterology. 2005 Apr; 128(4 Suppl 1): S68-73. Review.

Fasano A, Catassi C (b). Coeliac disease in children. Best Pract Res Clin Gastroenterol. 2005 Jun; 19(3): 467-78. Review.

Fasano A. Physiological, pathological, and therapeutic implications of zonulin-mediated intestinal barrier modulation: living life on the edge of the wall. Am J Pathol. 2008 Nov; 173(5): 1243-52.

Fasano A, Araya M, Bhatnagar S, et al. Federation of International Societies of Pediatric Gastroenterology, Hepatology, and Nutrition consensus report on celiac disease. J Pediatr Gastroenterol Nutr. 2008 Aug; 47(2): 214-9.

Fasano A. Novel therapeutic/integrative approaches for celiac disease and dermatitis herpetiformis. Clin Dev Immunol. 2012; 2012: 959061.

Fortunato F, Martinelli D, Cozza V, et al. Italian family paediatricians' approach and management of celiac disease: a cross-sectional study in Puglia Region, 2012. BMC Gastroenterol. 2014 Feb 20; 14: 38.

Fälth-Magnusson K, Franzén L, Jansson G, et al. Infant feeding history shows distinct differences between Swedish celiac and reference subjects. Pediatr Allergy Immunol 1996; 7: 1-7. 
Gangolli SD, van den Brandt PA, Feron VJ, et al. Nitrate, nitrite and N-nitroso compounds. Eur J Pharmacol. 1994; 292(1): 1-38.

Garampazzi A, Rapa A, Mura S, et al. Clinical pattern of celiac disease is still changing. J Pediatr Gastroenterol Nutr. 2007 Nov; 45(5): 611-4.

Gasbarrini GB, Mangiola F, Gerardi V, et al. Coeliac disease: an old or a new disease? History of a pathology. Intern Emerg Med. 2014 Apr; 9(3): 249-56.

Gee SJ: The coeliac affection. St Bartholomew's Hosp Rep 1888; 24:17-20.

George EK, Mearin ML, Franken HC, et al. Twenty years of childhood coeliac disease in The Netherlands: a rapidly increasing incidence? Gut. 1997 Jan; 40(1): 61-6.

Gheller-Rigoni AI, Yale SH, Abdulkarim AS. Celiac Disease: Celiac Sprue, Gluten-sensitive Enteropathy. Clin Med Res. 2004 Feb; 2(1): 71-72.

Giersiepen K, Lelgemann M, Stuhldreher, et al. ; ESPGHAN Working Group on Coeliac Disease Diagnosis. Accuracy of diagnostic antibody tests for coeliac disease in children: summary of an evidence report. J Pediatr Gastroenterol Nutr. 2012 Feb; 54(2):229-41.

Goggins MG, Shah SA, Goh J, et al. Increased urinary nitrite, a marker of nitric oxide, in active inflammatory bowel disease. Mediators Inflamm. 2001; Apr 10(2): 69-73.

Grabowski PS, England AJ, Dykhuizen R, et al. Elevated nitric oxide production in rheumatoid arthritis. Detection using the fasting urinary nitrate: creatinine ratio. Arthritis Rheum. 1996 Apr; 39(4):643-7.

Greco L, Mayer M, Grimaldi M, et al. The effect of early feeding on the onset of symptoms in celiac disease. J Pediatr Gastroenterol Nutr. 1985 Feb; 4(1):52-5.

Grodzinsky E, Hed J, Lieden, et al. Presence of IgA and IgG antigliadin antibodies in healthy adults as measured by micro-ELISA. Effect of various cutoff levels on specificity and sensitivity when diagnosing coeliac disease. Int Arch Allergy Appl Immunol. 1990; 92(2): 119-23.

Grodzinsky E, Franzen L, Hed J, et al. High prevalence of celiac disease in healthy adults revealed by antigliadin antibodies. Ann Allergy. 1992 Jul; 69(1): 66-70.

Grodzinsky E, Hed J, Skogh T. IgA antiendomysium antibodies have a high positive predictive value for celiac disease in asymptomatic patients. Allergy. 1994 Sep; 49(8): 593-7.

Green PH, Cellier C. Celiac disease. N Engl J Med. 2007 Oct 25;357(17): 1731-43.

Hansson T, Dannaeus A, Klareskog L. Cytokine-producing cells in peripheral blood of children with coeliac disease secrete cytokines with a type 1 profile. Clin Exp Immunol. 1999 May; 116(2): 246-50.

Hill ID, Dirks HM, Liptak GS et al.; North American Society for Pediatric Gastroenterology, Hepatology and Nutrition. Guideline for the diagnosis and treatment of celiac disease in child- 
ren: recommendations of the North American Society for Pediatric Gastroenterology, Hepatology and Nutrition. J PediaDytr Gastroenterol Nutr. 2005 Jan; 40(1): 1-19.

Hollén E, Forslund T, Högberg L, et al. Urinary nitric oxide during one year of gluten-free diet with or without oats in children with coeliac disease. Scand J Gastroenterol. 2006; 41(11): 1272-8.

Holm K, Mäki M, Vuolteenaho N, et al. Oats in the treatment of childhood coeliac disease: a 2-year controlled trial and a long-term clinical follow-up study. Aliment Pharmacol Ther. 2006; 23(10): 1463-72.

Holmgren-Peterson K, Fälth-Magnusson K, Magnusson KE, et al. Children with celiac disease express inducible nitric oxide synthase in the small intestine during gluten challenge. Scand J Gastroenterol. 1998; 33(9): 939-43.

Hommel KA, Mackner LM, Denson LA, et al. Treatment regimen adherence in pediatric gastroenterology. J Pediatr Gastroenterol Nutr. 2008 Nov; 47(5):526-43.

Horwitz A, Skaaby T, Kårhus LL, et al. Screening for celiac disease in Danish adults. Scand J Gastroenterol. $2015 \mathrm{Jul}$; 50(7):824-31. 17.

Hunt KA, Zhernakova A, Turner G, et al. Newly identified genetic risk variants for celiac disease related to the immune response. Nat Genet. 2008 ; 40:395-402.

Husby S, Koletzko S, Korponay-Szabó IR, et al; ESPGHAN Working Group on Coeliac Disease Diagnosis; ESPGHAN Gastroenterology Committee; European Society for Pediatric Gastroenterology, Hepatology, and Nutrition. J Pediatr Gastroenterol Nutr 2012 Jan; 54(1): 136-60.

Högberg L, Grodzinsky E, Stenhammar L. Better dietary compliance in patients with coeliac disease diagnosed in early childhood. Scand J Gastroenterol. 2003 Jul; 38(7): 751-4.

Högberg L, Laurin P, Fälth-Magnusson K, et al. Oats to children with newly diagnosed coeliac disease: a randomised double blind study. Gut. 2004; 53(5): 649-54.

Ivarsson A, Persson LA, Nyström L, et al. Epidemic of coeliac disease in Swedish children. Acta Paediatr. 2000 Feb; 89(2): 165-71.

Ivarsson A, Hernell $\mathrm{O}$, Stenlund $\mathrm{H}$, et al. Breast-feeding protects against celiac disease. Am J Clin Nutr. 2002 May; 75(5):914-21.

Jackson PT, Glasgow JF, Thom R. Parents' understanding of coeliac disease and diet. Arch Dis Child 1985; 60(7): 672-4.

Jadresin O, Misak Z, Sanja K, et al. Compliance with gluten-free diet in children with coeliac disease. J Pediatr Gastroenterol Nutr 2008; 47(3): 344-8.

Janatuinen EK, Pikkarainen PH, Kemppainen TA, et al. A comparison of diets with and without oats in adults with celiac disease. N Engl J Med 1995; 333(16): 1033-7. 
Janatuinen EK, Kemppainen TA, Julkunen RJ, et al. No harm from five year ingestion of oats in coeliac disease. Gut. 2002 Mar; 50(3):332-5.

Johnston SD, Rodgers C, Watson RG. Quality of life in screen-detected and typical coeliac disease and the effect of excluding dietary gluten. Eur J Gastroenterol Hepatol. 2004 Nov; 16(12):1281-6.

Kagnoff MF. Overview and pathogenesis of celiac disease. Gastroenterology 2005; 128(4 Suppl 1): S10-8.

Kakar S, Nehra V, Murray JA, et al. Significance of intraepithelial lymphocytosis in small bowel biopsy samples with normal mucosal architecture. Am J Gastroenterol. 2003 Sep; 98(9): 2027-33.

Kappinen K, Arnell H, Finkel Y, et al. Villous atrophy in pediatric celiac disease may be confined to the proximal partof duodenum. Abstracts: Poster Session Abstracts. Journal of Pediatric Gastroenterology \& Nutrition: June 2004 - Volume 39 - Issue - pp S202-S203.

Karell K, Louka AS, Moodie SJ et al.; European Genetics Cluster on Celiac Disease. HLA types in celiac disease patients not carrying the DQA1*05-DQB1*02 (DQ2) heterodimer: results from the European Genetics Cluster on Celiac Disease. Hum Immunol. 2003 Apr; 64(4): 469-77.

Kasarda DD. Gluten and gliadin: precipitating factors in coeliac disease. Proceedings of the seventh international symposium of coeliac disease. Tampere, Finland. 1996, pages:195-212.

Kilmartin C, Lynch S, Abuzakouk M, et al. Avenin fails to induce a Th1 response in coeliac tissue following in vitro culture. Gut. 2003 Jan; 52(1): 47-52.

Koskinen O, Villanen M, Korponay-Szabo I, et al. Oats do not induce systemic or mucosal autoantibody response in children with coeliac disease. J Pediatr Gastroenterol Nutr. 2009; 48(5): 559-65.

Kubes P. Nitric oxide modulates epithelial permeability in the feline small intestine. Am J Physiol. 1992 Jun; 262(6 Pt 1): G1138-42.

Kumar PJ, Walker-Smith J, Milla P, et al. The teenage coeliac: follow up study of 102 patients. Arch Dis Child 1988; 63(8): 916-20.

Ladinser B, Rossipal E, Pittschieler K. Endomysium antibodies in coeliac disease: an improved method. Gut. 1994 Jun; 35(6): 776-8.

Lamacchia C, Camarca A, Picascia S, et al. Cereal-based gluten-free food: how to reconcile nutritional and technological properties of wheat proteins with safety for celiac disease patients. Nutrients. 2014 Jan 29;6(2): 575-90.

Larsen FJ, Schiffer TA, Ekblom B, et al. Dietary nitrate reduces resting metabolic rate: a randomized, crossover study in humans. Am J Clin Nutr. February 5, 2014. 
Laurin P, Wolving M, Fälth-Magnusson K. Even small amounts of gluten cause relapse in children with celiac disease. J Pediatr Gastroenterol Nutr 2002 Jan; 34(1): 26-30.

La Vieille S, Dubois S, Hayward S, et al. Estimated levels of gluten incidentally present in a Canadian gluten-free diet. Nutrients. 2014 Feb 21; 6(2): 881-96.

Leja M, Shums Z, Nikitina-Zake L, et al. Prevalence estimation of celiac disease in the general adult population of Latvia using serology and HLA genotyping. United European Gastroenterol J. 2015 Apr; 3(2):190-9.

Lionetti E, Catassi C. New clues in celiac disease epidemiology, pathogenesis, clinical manifestations, and treatment. Int Rev Immunol. 2011 Aug; 30(4):219-31.

Lionetti E, Castellaneta S, Francavilla R, et al; SIGENP (Italian Society of Pediatric Gastroenterology, Hepatology, and Nutrition) Working Group on Weaning and CD Risk. Introduction of gluten, HLA status, and the risk of celiac disease in children. N Engl J Med.

2014 Oct 2; 371(14): 1295-303.

Ljungman G, Myrdal U. Compliance in teenagers with coeliac disease-a Swedish follow-up study. Acta Paediatr 1993; 82(3): 235-8.

Lohiniemi S, Mäki M, Kaukinen K, et al. Gastrointestinal symptoms rating scale in coeliac disease patients on wheat starch-based gluten-free diets. Scand J Gastroenterol. 2000 Sep; 35(9): 947-9.

Londono DM, van't Westende WP, Goryunova S, et al. Avenin diversity analysis of the genus Avena (oat). Relevance for people with celiac disease. Journal of Cereal Science 2013; 58: 170-177.

Losowsky M.S. A History of Coeliac. Disease Dig Dis 2008;26:112-120.

Ludvigsson JF, Ansved P, Fälth-Magnusson K, et al. Symptoms and signs have changed in Swedish children with coeliac disease. J Pediatr Gastroenterol Nutr. 2004 Feb; 38(2): 181-6.

Ludvigsson JF, Brandt L, Montgomery SM, et al. Validation study of villous atrophy and small intestinal inflammation in Swedish biopsy registers BMC Gastroenterol. 2009 Mar 11;9:19. doi: 10.1186/1471-230X-9-19.

Ludvigsson JF, Rubio-Tapia A, van Dyke CT, et al (a). Increasing incidence of celiac disease in a North American Population. Am J Gastroenterol. 2013 May; 108(5): 818-824.

Ludvigsson JF, Leffler DA, Bai JC, et al (b). The Oslo definitions for coeliac disease and related terms. Gut 2013 Jan; 62(1): 43-52.

Ludvigsson JF, Card TR, Kaukinen K, et al. Screening for celiac disease in the general population and in high-risk groups. United European Gastroenterol J. 2015 Apr; 3(2):106-20.

Lundberg JO, Weitzberg E, Gladwin MT. The nitrate-nitrite-nitric oxide pathway in physiology and therapeutics. Nat Rev Drug Discov. 2008 Feb; 7(2):156-67. 
Lundin KE, Nilsen EM, Scott HG, et al. Oats induced villous atrophy in coeliac disease. Gut. 2003 Nov; 52(11): 1649-52.

MacCulloch K, Rashid M. Factors affecting adherence to a gluten-free diet in children with celiac disease. Factors affecting adherence to a gluten-free diet in children with celiac disease. Paediatr Child Health. 2014 Jun; 19(6): 305-9.

Mahadeva S, Wyatt JI, Howdle PD. Is a raised intraepitehelial lymphocyte count with normal duodenal villous architecture clinically relevant? J Clin Pathol 2002; 55: 424-428.

Mariani P, Viti MG, Montouri M, et al. The gluten-free diet: a nutritional risk factor for adolescents with celiac disease. J Pediatr Gastroenterol Nutr. 1998; 27: 519-523.

Marsh MN. Gluten, major histocompatibility complex, and the small intestine. A molecular and immunobiologic approach to the spectrum of gluten sensitivity ('celiac sprue'). Gastroenterology. 1992 Jan; 102(1): 330-54.

Mayer M, Greco L, Troncone R, et al. Compliance of adolescents with coeliac disease with a gluten free diet. Gut 1991; 32(8): 881-5.

McGowan KE, Castiglione DA, Butzner JD. The changing face of childhood celiac disease in north america: impact of serological testing. Pediatrics. 2009 Dec; 124(6): 1572-8.

Meeuwisse, G. W. Diagnostic criteria in coeliac disease. (Discussion, European Society for Paediatric Gastroenterology). Acta Paediatrica Scandinavica, 59, 461. (1970).

Molberg O, Mcadam SN, Körner R, et al. Tissue transglutaminase selectively modifies gliadin peptides that are recognized by gut-derived T cells in celiac disease. Nat Med. 1998 Jun; 4(6): 713-7.

Moshage H. Nitric oxide determinations: much ado about NO.-thing? Clin Chem. 1997 Apr; 43(4):553-6.

Mubarak A, Nikkels P, Houwen R, et al. Reproducibility of the histological diagnosis of celiac disease. Scand J Gastroenterol. 2011 Sep; 46(9): 1065-73.

Mulder CJ, Bartelsman JF. Case-finding in coeliac disease should be intensified. Best Pract Res Clin Gastroenterol. 2005 Jun; 19(3): 479-86.

Murray JA, Herlein J, Mitros F, et al. Serologic testing for celiac disease in the United States: results of a multilaboratory comparison study. Clin Diagn Lab Immunol. 2000 Jul; 7(4): 5847.

Murray IA, Daniels I, Coupland K, et al. Increased activity and expression of iNOS in human duodenal enterocytes from patients with celiac disease. Am J Physiol Gastrointest Liver Physiol. 2002; 283(2): G319-26.

Murray JA. Celiac disease in patients with an affected member, type 1 diabetes, irondeficiency, or osteoporosis? Gastroenterology. 2005 Apr; 128(4 Suppl 1): S52-6. 
Mustalahti K, Lohiniemi S, Collin P, et al. Gluten-free diet and quality of life in patients with screen-detected celiac disease. Eff Clin Pract. 2002 May-Jun; 5(3): 105-13.

Mustalahti K, Catassi C, Reunanen A, et al. The prevalence of celiac disease in Europe: results of a centralized, international mass screening project. Ann Med. 2010 Dec; 42(8): 58795.

Myléus A, Ivarsson A, Webb C, et al. Celiac disease revealed in 3\% of Swedish 12-year-olds born during an epidemic. J Pediatr Gastroenterol Nutr 2009; 49(2): 170-6.

Mäki M, Kallonen K, Lahdeaho ML, et al. Changing pattern of childhood coeliac disease in Finland. Acta Paediatr Scand 1988; 77: 408-12.

Nachman F, Mauriño E, Vázquez H, et al. Quality of life in celiac disease patients: prospective analysis on the importance of clinical severity at diagnosis and the impact of treatment. Dig Liver Dis. 2009 Jan; 41(1):15-25.

Namatovu F, Sandström O, Olsson C, et al. Celiac disease risk varies between birth cohorts, generating hypotheses about causality: evidence from 36 years of population-based follow-up. BMC Gastroenterology 2014; 14: 59.

Newnham ED, Shepherd SJ, Strauss BJ, et al. Adherence to the gluten-free diet can achieve the therapeutic goals in almost all patients with coeliac disease: A five-year longitudinal study from diagnosis. J Gastroenterol Hepatol. 2015 Jul 24.

Oberhuber G, Granditsch G, Vogelsang H. The histopathology of coeliac disease: time for a standardized report scheme for pathologists. Eur J Gastroenterol Hepatol. 1999 Oct; 11(10): 1185-94.

Olén O, Gudjónsdóttir AH, Browaldh L, et al. Antibodies against deamidated gliadin peptides and tissue transglutaminase for diagnosis of pediatric celiac disease. J Pediatr Gastroenterol Nutr. 2012 Dec; 55(6): 695-700.

Olsson C, Hernell O, Hörnell A, et al. Difference in celiac disease risk between Swedish birth cohorts suggests an opportunity for primary prevention. Pediatrics. 2008 Sep; 122(3): 528-34.

Persliden J, Pettersson HB, Fälth-Magnusson K. Radiation dose at small intestinal biopsies in children: results of a national study. Acta Paediatr. 1996 Sep; 85(9):1042-6.

Persson LA, Ivarsson A, Hernell O. Breast-feeding protects against celiac disease in childhood-epidemiological evidence. Adv Exp Med Biol. 2002; 503: 115-23. Review.

Peräaho M, Kaukinen K, Paasikivi K, et al. Wheat-starch-based gluten-free products in the treatment of newly detected coeliac disease: prospective and randomized study. Aliment Pharmacol Ther. 2003 Feb 15;17(4):587-94.

Peräaho M, Kaukinen K, Mustalahti K, et al. Effect of an oats-containing gluten-free diet on symptoms and quality of life in coeliac disease. A randomized study. Gastroenterology 2004 Jan; 39(1): 27-31. 
Picarelli A, Di Tola M, Sabbatella L, et al. Immunologic evidence of no harmful effect of oats in celiac disease. Am J Clin Nutr. 2001 Jul; 74(1): 137-40.

Pietzak MM. Follow-up of patients with celiac disease: achieving compliance with treatment. Gastroenterology. 2005 Apr; 128(4 Suppl 1): S135-41.

Plugis NM, Khosla C. Therapeutic approaches for celiac disease. Best Pract Res Clin Gastroenterol. 2015 Jun; 29(3): 503-21.

Prause C, Ritter M, Probst C, et al. Antibodies against deamidated gliadin as new and accurate biomarkers of childhood coeliac disease. J Pediatr Gastroenterol Nutr 2009; 49:52.

Rachmilewitz D, Karmeli F, Okon E, et al. Experimental colitis is ameliorated by inhibition of nitric oxide synthase activity. Gut. 1995 Aug; 37(2): 247-55.

Rampertab SD, Pooran N, Brar P, et al. Trends in the presentation of celiac disease. Am J Med. 2006 April; 119(4): 355 e9-355 e14.

Rasane P, Jha A, Sabikhi L, et al. Nutritional advantages of oats and opportunities for its processing as value added foods - a review. J Food Sci Technol. 2015 Feb; 52(2): 662-75.

Rashid M, Cranney A, Zarkadas M, et al. Celiac disease: evaluation of the diagnosis and dietary compliance in Canadian children. Pediatrics 2005; 116(6): e754-9.

Ravikumara M, Tuthill DP, Jenkins HR. The changing clinical presentation of coeliac disease. Arch Dis Child. 2006 Dec; 91(12): 969-71.

Ravikumara M, Nootigattu VK, Sandhu BK. Ninety percent of celiac disease is being missed. J Pediatr Gastroenterol Nutr. 2007 Oct; 45(4): 497-9.

Reilly NR, Aguilar K, Hassid BG, et al. Celiac disease in normalweight and overweight children: clinical features and growth outcomes following a gluten-free diet. J Pediatr Gastroenterol Nutr. 2011 Nov; 53(5): 528-31.

Reilly NR, Green PH. Epidemiology and clinical presentations of celiac disease. Semin Immunopathol. $2012 \mathrm{Jul}$; 34(4): 473-8.

Ress K, Luts K, Rägo T, et al. Nationwide study of childhood celiac disease incidence over a 35-year period in Estonia. Eur J Pediatr. 2012 Dec; 171(12): 1823-8.

Rhodes P, Leone AM, Francis PL, et al. The L-arginine: nitric oxide pathway is the major source of plasma nitrite in fasted humans. Biochem Biophys Res Commun. 1995 Apr 17; 209(2): 590-6.

Richman E. The safety of oats in the dietary treatment of coeliac disease. Proc Nutr Soc. 2012 Nov; 71(4): 534-7.

Rodrigues AF, Jenkins HR. Investigation and management of coeliac disease. Arch Dis Child. 2008 Mar; 93(3): 251-4. 
Rodríguez-Díaz J, Banasaz M, et al. Role of nitric oxide during rotavirus infection. J Med Virol. 2006 Jul; 78(7):979-85.

Roma E, Panayiotou J, Karantana H, et al.Changing pattern in the clinical presentation of pediatric celiac disease: a 30-year study. Digestion. 2009; 80(3): 185-91.

Romanos J, Rosén A, Kumar V, et al; Prevent CD Group. Improving coeliac disease risk prediction by testing non-HLA variants additional to HLA variants. Gut. 2014 Mar; 63(3): 41522.

Rosén A, Ivarsson A, Nordyke $\mathrm{K}$, et al. Balancing health benefits and social sacrifices: a qualitative study of how screening-detected celiac disease impacts adolescents' quality of life. BMC Pediatr. 2011 May 10; 11: 32.

Rostami K, Kerckhaert J, Tiemessen R, et al. Sensitivity of antiendomysium and antigliadin antibodies in untreated celiac disease: disappointing in clinical practice. Am J Gastroenterol. 1999 Apr; 94(4): 888-94.

Rostom A, Dubé C, Cranney A, et al. The diagnostic accuracy of serologic tests for celiac disease: a systematic review. Gastroenterology. 2005 Apr; 128(4 Suppl 1): S38-46.

Samasca G, Sur G, Lupan I, et al. Celiac disease as an autoimmune condition. Cent Eur J Immunol. 2014; 39(3): 396-9.

Savilahti E, Kolho KL, Westerholm-Ormio M, et al. Clinics of coeliac disease in children in the 2000s. Acta Paediatr.2010 Jul; 99(7): 1026-30.

Shan L, Molberg Ø, Parrot I, et al. Structural basis for gluten intolerance in celiac sprue.

Science. 2002 Sep 27; 297(5590): 2275-9.

Sjöberg V, Hollén E, Pietz G, et al. Noncontaminated dietary oats may hamper normalization of the intestinal immune status in childhood celiac disease. Clin Transl Gastroenterol. 2014 Jun 26;5: e58.

Sollid LM. Coeliac disease: dissecting a complex inflammatory disorder. Nat Rev Immunol. 2002 Sep; 2(9): 647-55.

Sollid LM, Khosla C. Novel therapies for coeliac disease. J Intern Med. 2011 Jun; 269(6): 604-13.

Srinivasan U, Leonard N, Jones E, et al. Absence of oats toxicity in adult coeliac disease. BMJ. 1996 Nov 23; 313(7068): 1300-1.

Stenhammar L, Högberg L, Saalman R. The Pediatric Association recommends: Oats can be implemented in the gluten-free diet. Läkartidningen 2004; 101(18): 1610-1.

Stenhammar L, Högberg L, Danielsson L, et al. How do Swedish paediatric clinics diagnose coeliac disease? Results of a nationwide questionnaire study. Acta Paediatr. 2006 Nov; 95(11): 1495-7. 
Størsrud S (a), Olsson M, Arvidsson Lenner R, et al. Adult coeliac patients do tolerate large amounts of oats. Eur J Clin Nutr. 2003 Jan; 57(1): 163-9.

Størsrud S (b), Hulthén LR, Lenner RA. Beneficial effects of oats in the gluten-free diet of adults with special reference to nutrient status, symptoms and subjective experiences. $\mathrm{Br} \mathrm{J}$ Nutr. 2003 Jul; 90(1):101-7.

Sundqvist T, Laurin P, Fälth-Magnusson K, et al. Significantly increased levels of nitric oxide products in urine of children with celiac disease. J Pediatr Gastroenterol Nutr. 1998; 27(2): 196-8.

Szajewska H, Shamir R, Chmielewska A, et al., PREVENTCD Study Group. Systematic review with meta-analysis: early infant feeding and coeliac disease--update 2015. Aliment Pharmacol Ther. 2015 Jun; 41(11): 1038-54.

Taavela J, Kurppa K, Collin P, et al. Degree of damage to the small bowel and serum antibody titers correlate with clinical presentation of patients with celiac disease. Clin Gastroenterol Hepatol 2013; 11: 166-171.

Tanpowpong P, Broder-Fingert S, Katz AJ, et al. Age-related patterns in clinical presentations and gluten related issues among children and adolescents with celiac disease.

Theethira TG, Dennis M. Celiac disease and the gluten-free diet: consequences and recommendations for improvement. Dig Dis. 2015;33(2):175-82.

Thies F, Masson LF, Boffetta P, et al. Oats and bowel disease: a systematic literature review. Br J Nutr. 2014 Oct; 112 Suppl 2: S31-43.

Thomas HJ, Ahmad T, Rajaguru C, et al. Contribution of histological, serological, and genetic factors to the clinical heterogeneity of adult-onset coeliac disease. Scand J Gastroenterol 2009; 44: 1076-1083.

Tjellström B, Stenhammar L, Sundqvist T, et al. The effects of oats on the function of gut microflora in children with coeliac disease. OAliment Pharmacol Ther. 2014 May; 39(10):1156-60.

Tommasini A, Not T, Kiren V, et al. Mass screening for coeliac disease using antihuman transglutaminase antibody assay. Arch Dis Child. 2004; 89: 512-515.

Vader LW, de Ru A, van der Wal Y, et al. Specificity of tissue transglutaminase explains cereal toxicity in celiac disease. J Exp Med. 2002 Mar 4; 195(5): 643-9.

Vader LW, Stepniak DT, Bunnik EM, et al. Characterization of cereal toxicity for celiac disease patients based on protein homology in grains. Gastroenterology. 2003 Oct; 125(4): 110513.

Van Heel DA, Franke L, Hunt KA, et al. A genome-wide association study for celiac disease identifies risk variants in the region harboring IL2 and IL21. Nat Genet. 2007 Jul; 39(7): 8279 . 
Van Straaten EA, Koster-Kamphuis L, Bovee-Oudenhoven IM, et al. Increased urinary nitric oxide oxidation products in children with active coeliac disease. Acta Paediatr. 1999; 88(5): 528-31.

Veeraraghavan G, Leffler DA, Kaswala DH, et al. Celiac disease 2015 update: new therapies. Expert Rev Gastroenterol Hepatol. 2015 Jul; 9(7):913-27.

Verdon CP, Burton BA, Prior RL. Sample pretreatment with nitrate reductase and glucose-6phosphate dehydrogenase quantitatively reduces nitrate while avoiding interference by NADP + when the Griess reaction is used to assay for nitrite. Anal Biochem. 1995; 224 (2):502-8.

Villarreal D, Grisham MB, Granger DN. Nitric oxide donors improve gut function after prolonged hypothermic ischemia. Transplantation. 1995 Mar 15; 59(5): 685-9.

Volta U, Cassani F, De Franchis R, et al. Antibodies to gliadin in adult coeliac disease and dermatitis herpetiformis. Digestion. 1984; 30(4): 263-70.

Volta U, Villanacci V. Celiac disease: diagnostic criteria in progress. Cellular \& Molecular Immunology (2011) 8, 96-102.

Vriezinga SL, Auricchio R, Bravi E, et al. Randomized feeding intervention in infants at high risk for celiac disease. N Engl J Med. 2014 Oct 2; 371(14): 1304-15.

Walker-Smith JA. Samuel Gee and the celiac affection. In: Coeliac disease: one hundred years. Eds. Kumar PJ \& Walker-Smith JA, 1988, p. 1-10.

Wallace JL, Miller MJ. Nitric oxide in mucosal defense: a little goes a long way. Gastroenterology. 2000 Aug; 119(2): 512-20.

Webb C, Myléus A, Norström F, et al. High adherence to a gluten-free diet in adolescents with screening-detected celiac disease. J Pediatr Gastroenterol Nutr. 2015 Jan; 60(1): 54-9.

Weile B, Hansen BF, Hägerstrand I, et al. Interobserver variation in diagnosing coeliac disease. A joint study by Danish and Swedish pathologists. APMIS. 2000 May; 108(5): 380-4.

Weimer K, Gulewitsch MD, Schlarb AA, et al. Placebo effects in children: a review. Pediatr Res. 2013 Jul; 74(1): 96-102.

Weinberg JB, Lang T, Wilkinson WE, et al. Serum, urinary, and salivary nitric oxide in rheumatoid arthritis: complexities of interpreting nitric oxide measures. Arthritis Res Ther. 2006;8(5): R140.

White B. Diagnosis and treatment of urinary tract infections in children. Am Fam Physician. 2011; 83(4): 409-15.

White LE, Bannerman E, McGrogan P, et al. Childhood coeliac disease diagnoses in Scotland 2009-2010: the SPSU project. Arch Dis Child. 2013 Jan; 98(1): 52-6. 
Whyte LA, Jenkins HR. The epidemiology of coeliac disease in South Wales: a 28-year perspective. Arch Dis Child. 2013 Jun; 98(6): 405-7.

Wijmenga C, Gutierrez-Achury J. Celiac disease genetics: past, present and future challenges. J Pediatr Gastroenterol Nutr. 2014 Jul; 59 Suppl 1: S4-7.

Wolters V, Vooijs-Moulaert AF, Burger $\mathrm{H}$, et al. Human tissue transglutaminase enzyme linked immunosorbent assay outperforms both the guinea pig based tissue transglutaminase assay and anti-endomysium antibodies when screening for coeliac disease. Eur J Pediatr. 2002 May; 161(5): 284-7.

Wong RC, Wilson RJ, Steele RH, et al. A comparison of 13 guinea pig and human anti-tissue transglutaminase antibody ELISA kits. J Clin Pathol. 2002 Jul; 55(7): 488-94.

Ximenes MI, Rath S, Reyes FG. Polarographic determination of nitrate in vegetables. Talanta. 2000; 51(1): 49-56.

Zawahir S, Safta A, Fasano A. Pediatric celiac disease. Curr Opin Pediatr. 2009 Oct; 21(5): 655-60.

Zingone F, West $\mathrm{J}$, Auricchio R, et al. Incidence and distribution of coeliac disease in Campania (Italy): 2011-2013. United European Gastroenterol J. 2015 Apr; 3(2): 182-189.

Ågardh D, Lee HS, Kurppa K, et al.;TEDDY Study Group. Clinical features of celiac disease: a prospective birth cohort. Pediatrics.2015 Apr; 135(4): 627-34.

Änggård E. Nitric oxide: mediator, murderer, and medicine. Lancet. 1994 May 14;343(8907): 1199-206. 


\section{Papers}

The articles associated with this thesis have been removed for copyright reasons. For more details about these see:

http://urn.kb.se/resolve?urn=urn:nbn:se:liu:diva-122371 